\title{
Ranking Economics Departments in Europe: A statistical approach
}

\author{
Michel Lubrano $^{1} \quad$ Luc Bauwens ${ }^{2} \quad$ Alan Kirman $^{3}$ \\ Camelia Protopopescu ${ }^{4}$
}

May 2003

\begin{abstract}
We provide a ranking of economics departments in Europe and we discuss the methods used to obtain it. The JEL CD-ROM serves as a database for a period covering 10 years. Journals are ranked using a combination of expert opinions and citation data to produce a scale from 1 to 10 . The publication output and habits of fifteen European countries plus California are then compared. Individuals with a contribution greater than a predetermined minimum level are regrouped into departments which are ranked according to their total scores. A standard deviation is provided to underline the uncertainty of this ranking.
\end{abstract}

JEL Classification: I29, D63, C12, C14

Keywords: Ranking economics departments, journal ranking, inequality index, stochastic dominance, testing.

\section{Introduction}

There is a vast literature on how to rank economics departments in the USA. Almost all of this work concerns ranking the research output of the departments in question. Some of the most recent references are Conroy and Dusansky (1995), Dusansky and Vernon (1998), Feinberg (1998), and Griliches and Einav (1998). If we turn to Europe, there is the earlier work of Kirman and Dahl (1994) and the more recent paper of Kalaitzidakis, Mamuneas and Stengos (1999). Elements of comparison between European and US departments are given in the last reference. Some authors have focused on individual European countries: Combes and Linnemer (2001) on France, Bauwens (1999) on Belgium, van Damme (1996) on the Netherlands. Coupé (2000) was one of the first to face the challenge of obtaining a world ranking.

To compare and rank European economics departments, it is useful to have in mind the paradigm of a graduate student looking for a PhD program in Europe. He will be looking first for a supervisor (a person) and second for a scientific environment (an institution). How should he judge the institutions and individuals he wishes to consider? In both cases he may use reputation as as criterion but he is

\footnotetext{
${ }^{1}$ GREQAM-CNRS, Centre de la Vieille Charité, 2 rue de la Charité, F-13002 Marseille, France; email: lubrano@ehess.cnrs-mrs.fr. Corresponding author.

${ }^{2} \mathrm{CORE}$ and Department of Economics, Université catholique de Louvain, Belgium; email: bauwens@core.ucl.ac.be.

${ }^{3}$ GREQAM-EHESS, Centre de la Vieille Charité, 2 rue de la Charité, F-13002 Marseille, France; email: kirman@ehess.cnrs-mrs.fr.

${ }^{4}$ GREQAM, Centre de la Vieille Charité, 2 rue de la Charité, F-13002 Marseille, France.
} 
immediately faced with the problem of discerning the basis of that reputation. One method, which is not without merit, is to use the rankings proposed by peers. This avoids the problem of evaluating the activities on which the reputation is based. However, this merely delegates the basic problem to others. To adopt a more scientific approach one has to systematically evaluate the performance of individuals and then the institutions to which they belong.

Individuals employed by research and teaching institutions have multiple activities which may or may not lead to tangible outputs. They teach, they supervise PhD students, they publish articles and books, they act as referee for journals, sometimes they act as scientific editors for those journals. They gain a reputation among their colleagues by being elected as distinguished members of a scientific society or even president of that society. Finally they can win scientific prizes, the most important one being the Nobel Prize. Publications in journals are the most visible and well known output of researchers. Most published rankings of departments are based on a more or less sophisticated counting of publications. However, one must keep in mind several facts which may offset the overwhelming weight given to articles:

- Books are reputed not to carry much weight in economics. However, some books in economics are very often cited and perceived as major contributions. Books are generally recognised as major contributions in other social sciences. The main difficulty is that it seems difficult to say on a priori grounds if a book is good or not while it seems easier to say that an article is published in a good or in a bad journal.

- When electing a person as a member of a scientific association, or nominating him for a scientific prize, the jury takes into account mostly the impact of his scientific achievement in his field and not the large number of his publications. But it seems extremely difficult to quantify this procedure.

A ranking procedure based solely on published articles rapidly reaches its limits while it seems difficult to propose a reasonable and systematic alternative. Even if we are prepared to accept a bibliometric analysis of journal articles as a proper basis for ranking individuals we are faced with two problems.

Which journals should be taken into account and how much weight should be assigned to the articles that appear in them? One approach is not to weight the journals at all but simply to take the citations of the individual articles they contain and to weight them by the latter. Such a method has obvious drawbacks. Why was the article cited? In some cases it may be because of a mistake the article contains. In which journals was it cited? If it is a recent article it will be unfairly treated. We will come back to this in more detail. However, it should be clear that even if there is complete agreement with the criteria for evaluating the published output of an individual, some randomness remains. Do the papers published by the author in the period considered reflect his average performance? This may not be the case even if one claims that there is no randomness in the acceptance of papers (see for example, Gans and Shepherd 1994).

The next problem is one of definition, aggregation and attribution. If we are interested in ranking institutions we have to specify what we mean by the latter term. We then have to assign individuals to these institutions which organise research and teaching. When one uses the term institution here one thinks immediately of universities, departments, research centres... Many factors undermine this apparent simplicity. Individuals have specialities and have a tendency to group themselves into research centres. Consequently, a department may be good in some fields, and not so good in other fields. So the comparison between departments can be made in several ways. The role of research centres may be important in certain countries, we are thinking in particular of the French system. In their study, Kirman and Dahl (1996) pointed out the numerical importance of the University of Paris I, but without disaggregating this University into its research centres. So it is difficult to obtain a precise picture. On the other hand, focusing too much on disaggregated entities as did Combes and Linnemer (2001) may also be misleading because $\mathrm{PhD}$ students are enrolled at a University and not at a research centre, even if they may undertake their research in a research centre. Finally, we have to point out many errors contained in the various published rankings due to the difficulty of defining the institutions involved which, in turn, involves knowing the peculiarities 
of any particular national system. We noted many errors concerning the French system, because we know it rather well, but other readers will certainly find mistakes for other educational systems. Once again, even if there were complete agreement on the appropriate definition of institutions the problem of assigning individuals to institutions remains and involves some randomness. Where people are can be determined either by examining the lists of members of institutions or by accepting the affiliation they give when they publish an article. Neither method is foolproof and they represent two different points of view. Are we interested in measuring the "human capital" currently present in a department or are we interested in knowing which departments provide the most favourable environment for research, in which case we should look at where authors were when they submitted their papers. Once again there is considerable randomness here.

Starting then from the viewpoint that we are confronted with a random process, that of the production of individuals' publications and their appearance in a certain number of academic journals, we can now turn to the purpose of our investigation and explain the approach that we have adopted. Our aim is to contribute to the evaluation of European economics departments and to the comparison of top European economics departments to those in California, a state comparable in size to a large European country. We proceed by analysing the output of individuals and then assign individuals to institutions and aggregate.

Our analysis differs from the standard literature on the subject in several respects. The available bibliographical databases give a partial view of individual activity which, as we have already mentioned, we consider as a random variable. Statistical variability is explained by several facts: the time between submission and publication is random, the final decision of the editor is influenced by the choice he has made when selecting his referees, the probability of being accepted depends on the choice made at the time of submission and this may not be directly related to the quality of the journal, the journal may or may not be referenced in the database...

In order to get a plausible estimation of the individual activity of an author, we have to observe this random variable over a reasonably long period. We have chosen ten years. Bauwens (1999) for instance observed considerable variability in individual rankings between two shorter periods of time. If we wish to provide reliable rankings, we have to smooth out this type of variability. By considering the data over the whole period we obtain a distribution of performances of the individual researchers in a given country. Lubrano and Protopopescu (2003) made a first comparison of countries using the tools of stochastic dominance. In the next stage, we allocate individuals to institutions, so that we can compare distributions of individuals, but regrouped in institutions rather than in countries. The performance of an institution can be measured in various ways: as the total number of individuals having a publication output greater than a given threshold $z$; or as the sum of the scores obtained by those individuals. We can then provide a global ranking of institutions, but we consider that this ranking is a particular realisation of a random process. This implies that two institutions with different observed rankings can be statistically equivalent. We provide a formal statistical test for deciding wether the different rankings of institutions are indeed statistically significant.

The paper is organised as follows. In section 2, we spell out and compare the available sources of information. Section 3 justifies the method we have chosen for ranking journals. Section 4 analyses the different publication practices across the nations that we consider and compares them to California. Section 5 defines the conditions under which a ranking is feasible. Section 6 details the statistical procedure for measuring and testing and relates it to the economics of academic inequality. Section 7 provides a global ranking of institutions. Section 8 compares top European departments to those in California. Section 9 concludes.

\section{Available sources of information}

In the field of economics, we have two different sources: the Journal of Economic Literature and the Social Science Citation Index which do not provide overlapping information. 


\subsection{The Social Science Citation index}

The Institute of Scientific Information, a private institution based in Philadelphia, maintains a huge database covering a large number of scientific journals. It edits two CD-ROMs, the SSCI (Social Science Citation Index) and the SCI (Science Citation Index) which contain the references of journal articles published in one year and the citations made in those articles. The SSCI covers most of the social sciences, including economics and management. Its coverage is better than that of the JEL CD-ROM for finance and management, but must be considered to be deficient for pure economics as only 167 economic journals are indexed. National journals, statistical journals (like JASA which are indexed in the SCI) are often missing. But professional journals are included. At the end of each year, the Journal Citation Reports provides statistics on citations and computes various indicators including the now well known "impact factor".

\subsection{The Journal of Economic Literature}

The Journal of Economic Literature (JEL) CD-ROM reports the cumulative content of 681 journals, starting for some of them in 1969. These journals cover the basic fields of general economics but also include specialised fields like econometrics, some parts of statistics, game theory or history and various domains of application such as health, labour, industrial organisation, finance, management. A large place is devoted to national journals. The JEL and its associate CD-ROM are published by the American Economic Association. We prefer to use this database because it gives a better coverage of the overall activity of economists. Moreover, in one single CD-ROM it covers 15 years, while each SSCI CD-ROM is devoted to a single year.

\section{Measuring the score of an author}

The van Damme (1996) formula is an aggregation rule to determine the score of an author.

Definition 1 A researcher $i$ is attributed a score $q_{i, j}$ for the publication $p_{j}$ he coauthored and that appeared during year $t$. This score is defined by

$$
q_{i, j}=\frac{b\left(p_{j}\right)}{a\left(p_{j}\right)} v\left(p_{j}\right)
$$

where $b(p)$ is a number related to the length of the publication, a $(p)$ is a number related to the number $n$ of authors of the publication and $v(p)$ is related to the quality of the publication. The total score $s_{i, t}$ of a researcher $i$ during year $t$ is equal to the sum of the scores of the $n_{i, t}$ publications to which he contributed during year $t$ :

$$
s_{i, t}=\sum_{j=1}^{n_{i, t}} q_{i, j}
$$

We should explain the application of this formula by looking in details at each of its terms. We shall devote most of our discussion to journal ranking or in other terms how to specify the function $v(p)$.

\subsection{Journal ranking}

Several methods have been used and they may be grouped into two categories: opinion surveys on the one hand and citation analysis, as emphasised for instance in van Damme (1996) on the other hand. There is a recent tendency to prefer rankings based on impact factors. However, as we show below, impact factors are not as objective as might be thought and should be used with care. A method combining both sources of information can bring new insights to the field. 


\subsubsection{Opinion surveys versus citation analysis}

The Delphi method is certainly the most elaborate of the subjective methods of ranking. Each expert in a group assesses his opinion independently of the others in a first round. In a second round, his ranking is positioned against the ranking expressed by the rest of the group. He has then the right to revise or maintain his ranking. This method avoids the bias that arises from open discussions. But its implementation is time consuming. So most of the time, people involved in ranking journals simply skip the second round. This seems to be the case for Combes and Linnemer (2001) who ranked 307 of the 681 journals reported in the JEL database into five groups using expert opinions. The VSNU (Dutch Society of Universities) ranking results from open discussion of the committee. It considers also 5 categories (A to E) for 1383 economics and management journals which have been used by Dutch economists in the past. This ranking has won the reputation of being biased and has been abandoned by Dutch economists. The bias comes from the open discussion and strategic behaviour of the ranking committee which was composed by deans who knew the final use of their ranking: the evaluation of their own departments.

Citation analysis is based on the data provided by the Journal of Citation Reports (JCR). The JCR data gives among other things the impact factor associated to each of the 166 economic journals present in the SSCI:

Definition 2 The impact factor at time $t$ of a journal is given by the ratio between the number of citations made to that journal by a reference group of journals at time $t$ to articles published at times $t-1$ and $t-2$ by that journal, and the total number of articles published by that journal at time $t-1$ and $t-2$.

The importance of a journal is measured by the number of times it is quoted by other journals, corrected for size effects. Once this figure is obtained (it is directly available from the JCR), journals can be ranked accordingly. van Damme (1996) claimed that citation data provide an objective measure to rank journals which should be preferred to any other. CentER of Tilburg University uses it to rank Dutch economists and Dutch economics departments.

\subsubsection{A critical appraisal of impact factors}

The direct use of impact factors has several drawbacks. ISI itself in its web site ${ }^{1}$ recommends not to use these data for ranking journals. We can note immediately that the value of an impact factor first varies from year to year (it is a measure of the recent relevance or influence of the articles published in the journal) and second is a function of the reference group of journals (Econometrica appears in two databases, SSCI and SCI, and thus receives two different impact factors). Impact factors are not unique, can be manipulated and do not automatically represent an academic appraisal.

- There are techniques for increasing the number of citations for a journal. Among the most well known ones are publishing surveys and editing special issues on a given topic. This explains the very high score of the Journal of Economic Literature.

- Different scientific areas have different citations habits thus making comparisons hazardous. For instance, math journals cite other journals far less than economics journals do. Consequently, very formalised journals like the Journal of Mathematical Economics and Econometric Theory receive a low impact factor. van Damme (1996) argues that the JME covers a very narrow field that has a decreasing influence in the profession. But Cribari-Neto et al. (1999) note that Econometric Theory receives most of its citations from very high standard journals like Econometrica and the Journal of Econometrics both of which have high impact factors. Its indirect influence on the profession is thus much higher than its impact factor would lead one to infer.

\footnotetext{
${ }^{1} \mathrm{http}: / /$ www.isinet.com/isi/index.html
} 
- The audience of a journal is inversely proportional to its technicality. The SSCI contains journals which are not academic journals such as The Economist, but which receive a high impact factor (7.24 in 1994 for The Economist). Clearly this journal cannot be ranked on the same footing as Econometrica which received a mere 2.36 the same year. Usually, this type of journal is excluded from the ranking. The SSCI contains numerous semi professional journals which have a high impact factor, but a rather low academic content and which cannot be so easily excluded from the ranking. These journals are over-weighted in a ranking based solely on impact factors.

Several attempts have been made to cope with these deficiencies.

- Cribari-Neto et al. (1999) who were interested in ranking departments in the field of theoretical econometrics, defined a somewhat longer term measure. They consider 11 journals for the 11 year period 1986-1996. They computed an average impact factor defined as the total number of citations made to a journal by the 10 other journals during this period divided by the total number of articles published by that journal during this period. Table 2 reproduces these results. Comparing column 2 and column 3 shows that for top journals the valuation is not significantly different. There are differences for more specialised journals such as Econometric Theory and the Journal of Applied Econometrics, showing for those journals the importance of correctly selecting the reference group of journals.

- Liebowitz and Palmer (1984) build on the idea that it is better for a journal to be cited by a good journal than by a bad journal. They proposed to weight a citation by the quality of the journal which makes this citation. As quality is measured by citations, this is clearly an iterative process. Amir (2001) shows that this process converges due to a Markov property. But he also shows that an inadequate choice of the reference group for journals at the boundary of the field can explain some of the inconsistencies found in the updated rankings of Laband and Piette (1994).

- Bauwens (1998) combines (multiplies) the short term indicator given by the SSCI impact factor with the longer term indicator given by the total number of citations for a given year in order to mix a short term and a longer term indicator. He then defines a step function which maps the obtained score into 5 categories given by integers from 1 to 5 .

- Burton and Phimister (1995) try to incorporate long term information to determine what are the 20 "core journals". Instead of simply multiplying the above two criteria, they use the method of Data Envelopment Analysis.

\subsubsection{Combining subjective opinions and citation data}

We want to arrive at a ranking for most of the 681 journals appearing in the JEL database. By most we mean that it is not worth spending energy for ranking a journal that host less than 10 papers for any given country over the last 10 years. This reduces the number of significant journals to 505 .

We cannot use the information contained in the VSNU ranking for the reasons mentioned above. We are then left with the Combes and Linnemer ranking covering 307 journals. We asked to a single expert to update this ranking and complete it to arrive at a ranking of 505 journals giving grades between 1 and 10 (more precisely five classes 1, 2, 4, 6, 8, 10). We did not give him any information on impact factors for that first step.

In a second step, we collected citation data available for 364 journals in the fields of economics, finance and management (those used in Bauwens 1998). We multiplied the raw impact factor by the total number of citations and converted that number into an index between 1 and 10 according to the rule stated in Table 1 . Not all of this information can be used, as only 167 of these journals appear in the JEL database. ${ }^{2}$ In a third step, we communicated this information to the expert and asked

\footnotetext{
${ }^{2}$ This is the reason why we have 69 journals graded between 6 and 10 instead of the 121 appearing in Table 1 . The list is given in the appendix.
} 
Table 1: From citation data to classes

\begin{tabular}{l|c|c|c|c|c|c}
\hline Impact $\times$ citation & $>5000$ & $>1000$ & $>250$ & $>100$ & $>25$ & $>0$ \\
\hline Corresponding Index & 10 & 8 & 6 & 4 & 2 & 1 \\
Number of journals & 12 & 31 & 78 & 53 & 84 & 106 \\
\hline
\end{tabular}

him to update his judgements in view of this new information. This is a particular application of the Delphi method. When the subjective and the database rankings differed, the expert modified some of his judgements, but most of the time maintained them. There are 19 journals for which there was a discrepancy greater than 2 between the two rankings at the end of this procedure. The subjective ranking favours academic journals which are penalised by low citations and penalises professional or management journals which are at the margin of the field. This is in agreement with some of the comments we made concerning impact factors. The complete ranking is available on the web. ${ }^{3}$ It gives the ranking of 505 journals using subjective opinions updated by citation data.

The van Damme formula implies that 10 articles in journals graded 1 are worth 1 article in a journal graded 10. Many people would object to such an equivalence and consequently advocate for a much sharper classification of journals. For instance the blue ribbon ranking (as reported in Combes and Linnemer 2001) gives a weight $v(p)$ of zero to most journals and considers only publications made in a list of eight top generalist journals: American Economic Review, Econometrica, Journal of Economic Theory, Journal of Political Economy, Quarterly Journal of Economics, Review of Economic Studies, International Economic Review, Review of Economics and Statistics. This option is somehow extremist as it excludes in particular the best specialised journals such as the Journal of Econometrics, the Journal of Public Economics and the Journal of Finance. Burton and Phimister (1995) adopt a somehow lager view as they stand for a list of 20 "core journals". We took the even softer option of considering a list of the 69 journals having a score greater than or equal to 6 in our global ranking. With this option, $v(p)$ covers the range $[6,10]$ for the 69 journals of this list and is equal to zero for the other journals. We can thus obtain a second ranking of institutions which both provides a reasonably fair evaluation of the scientific activity of authors present in a department while avoiding treating output in an excessively homogenous way.

\subsection{Defining the other terms of the formula}

An obvious candidate for $a(p)$ is the number of coauthors. If this coefficient is meant to allocate the merit of the publication between its authors, choosing $a(p)=n$ does not promote collaboration which is central in modern scientific research. On the other hand, coauthors may belong to different institutions and in this case $a(p)$ plays the role of allocating the merit of the publication between different institutions. An exact aggregation formula thus requires $a(p)=n$. However, there are large and small institutions. In small institutions, authors may have a larger tendency to find outside coauthors than their counterparts in large institutions. So choosing $a(p)=n$ penalises small institutions and introduce an asymmetry of treatment. Consequently, we have chosen $a(p)=\sqrt{n}$ as suggested by Cribari-Neto et al. (1999).

Van Damme and his followers have chosen $b(p)$ to be a linear function of the number of pages of the article. Cribari-Neto et al. (1999), as well as many other authors, standardise the size of the pages. Some people count pages with respect to the page size of the American Economic Review, while Cribari-Neto et al. (1999) standardise with respect to the page size of Econometrica. The idea is to differentiate between notes and articles with the assumption that a short article has less scientific value than a long article.

The average number of standardised pages may be very different between journals. If we restrict our attention to the 11 econometric journals examined in Cribari-Neto et al. (1999) this number

\footnotetext{
${ }^{3}$ http://durandal.cnrs-mrs.fr/PP/lubrano/rankings/mixrank.xls
} 
ranges from 10 to 23 standardised pages. As a consequence, the use of the van Damme formula implies that journals with the same impact factor will not be considered as equivalent just because they have a different average number of standardised pages. In Table 2, we reproduce some of the data of Cribari-Neto et al. (1999). Average impact factor (AIF) is given in column 3 and average

Table 2: Page impact on Journal ranking

\begin{tabular}{llcccc}
\hline \hline Journal & $\begin{array}{l}1994 \\
\text { I.F. }\end{array}$ & $\begin{array}{c}\text { Average } \\
\text { I.F. }\end{array}$ & $\begin{array}{c}\text { Average } \\
\text { length }\end{array}$ & $\begin{array}{c}\text { A.I.F } \\
\text { rank. }\end{array}$ & $\begin{array}{c}\text { A.I.P.× A.L. } \\
\text { rank. }\end{array}$ \\
\hline Econometrica & 2.36 & 2.46 & 20.31 & 1 & 1 \\
Rev. of Eco. Studies & 1.70 & 1.61 & 22.60 & 2 & 2 \\
JASA & $1.24^{*}$ & 1.34 & 17.53 & 3 & 3 \\
J. of Econometrics & 1.20 & 1.06 & 21.02 & 4 & 4 \\
Annals of stat. & $0.78^{*}$ & 1.03 & 16.59 & 5 & 5 \\
Biometrika & $0.83^{*}$ & 0.97 & 10.45 & 6 & 8 \\
JBES & 0.63 & 0.78 & 17.97 & 7 & 7 \\
J. of Applied Ecot. & 0.37 & 0.71 & 20.55 & 8 & 6 \\
Rev. of Eco. and Stat. & 0.51 & 0.59 & 10.81 & 9 & 11 \\
Int. Eco. Review & 0.43 & 0.48 & 17.18 & 10 & 10 \\
Econometric Theory & 0.35 & 0.43 & 20.23 & 11 & 9 \\
\hline Impact Factors (I.F.) are computed from the SSCI except when a ${ }^{*}$ indicates the SCI. \\
A.I.F. means average impact factor and A.L. average length (see Cribari-Neto et al. \\
1994).
\end{tabular}

length (AL) in column 4. In column 5, we rank the eleven journals according to their AIF. The last column show how this ranking is modified when considering the product $A I F \times A L$ which is what the van Damme formula does. This is a sufficient reason to select $b(p)=1$. An additional reason would be that notes are sometimes more cited than plain articles and consequently that the difference between notes and plain articles should not be overemphasised.

\section{Comparing European countries to California}

We used the version of the JEL CD-ROM covering the period 1984-2000/09 from which we retained only 1991-2000 because of lesser data quality before (missing affiliations for instance). We have selected the $15 \mathrm{EU}$ countries, excluding Luxembourg which has no academic institution, but including Norway which, while not being an EU member, is nevertheless very close to the other Nordic countries. We have put Cyprus and Greece together.

\subsection{Economic articles published in the world}

Table 3: Economics articles published in the world as reported in the JEL database

\begin{tabular}{l|ccccc}
\hline \hline year & 1991 & 1992 & 1993 & 1994 & 1995 \\
articles & 11852 & 13025 & 13415 & 14317 & 15688 \\
\hline year & 1996 & 1997 & 1998 & 1999 & 2000 \\
articles & 17494 & 17988 & 18897 & 17846 & 5641 \\
\hline
\end{tabular}

Table 3 shows that the number of published economic articles in the world is steadily rising. The decline in the last two years is linked to the delay in updating the database. We can say that 
the number of published articles has doubled in ten years. The JEL database contains a total of 146163 articles out of which European countries published 41930 which represents $29 \%$ of the total. In comparison, US departments published 49460 articles in the same period (34\%). Europe in the broad sense has a number of publications which is comparable to the U.S., even if it is slightly smaller.

\subsection{The choice of California as a US proxy}

We can infer from Coupé (2000) or Combes and Linnemer (2001) that it is both difficult and unfair to compare each European country to the USA, because of a disproportion in size. The whole USA had 281.4 millions inhabitants in 2000 while the largest European country (Germany) had 82.2 millions. Our idea is to take as a reference, not the whole USA, but a state which can be considered as representative. We have selected California. The population of this state was 33.9 millions in 2000. This makes it the most populated state of the USA and comparable in size to large or medium sized European countries. Its population is slightly less than Spain and its surface is slightly less than France. The EDRIC web site ${ }^{4}$ credits it with 143 institutions for economics. From that listing, we have counted 52 universities with an economics or a business department. Dusansky and Vernon (1998) indicate that out of the 50 top US economics departments, 8 are located in California. With $12 \%$ of the US population, this state has $16 \%$ of the best US economics departments. This suggest that the choice of California is not unreasonable as a representative US state.

\subsection{Quantitative indicators}

Table 4 gives numerical indications about the information we have extracted from the database. Column 2 gives the number of articles and column 3 the number of journals involved in publishing these articles. Column 4 gives the number of authors. We have distinguished two main panels in this

Table 4: Comparing countries

Quantitative indicators

\begin{tabular}{l|cccc|ccc}
\hline \hline Country & $\begin{array}{c}\text { Articles } \\
\text { total }\end{array}$ & Journals & Authors & $\begin{array}{c}\text { Foreign } \\
\text { coauthors }\end{array}$ & $\begin{array}{c}\text { Pop. } \\
\text { (millions) }\end{array}$ & $\begin{array}{c}\text { Aut. } \\
\text { / pop. }\end{array}$ & $\begin{array}{c}\text { Eco. } \\
\text { Dept. }\end{array}$ \\
\hline Austria & 842 & 247 & 460 & $15 \%$ & 8.1 & 56.67 & 12 \\
Belgium & 1656 & 298 & 806 & $19 \%$ & 10.3 & 76.99 & 16 \\
Denmark & 919 & 253 & 463 & $14 \%$ & 5.4 & 85.74 & 8 \\
Finland & 713 & 174 & 433 & $16 \%$ & 5.2 & 83.27 & 18 \\
Greece & 861 & 245 & 403 & $16 \%$ & 10.9 & 36.76 & 12 \\
Ireland & 460 & 143 & 256 & $17 \%$ & 3.8 & 67.11 & 8 \\
Netherlands & 3478 & 415 & 1793 & $14 \%$ & 16.0 & 111.94 & 10 \\
Norway & 940 & 233 & 470 & $13 \%$ & 4.5 & 104.44 & 7 \\
Portugal & 260 & 117 & 144 & $25 \%$ & 10.0 & 14.40 & 15 \\
Sweden & 1652 & 304 & 868 & $12 \%$ & 8.9 & 97.42 & 21 \\
\hline France & 5118 & 397 & 2698 & $17 \%$ & 59.2 & 46.00 & 70 \\
Germany & 4191 & 406 & 2506 & $13 \%$ & 82.2 & 30.19 & 98 \\
Italy & 3545 & 355 & 1921 & $14 \%$ & 57.8 & 32.87 & 72 \\
Spain & 2338 & 307 & 1527 & $14 \%$ & 39.8 & 38.37 & 48 \\
UK & 13351 & 613 & 6656 & $15 \%$ & 60.0 & 115.60 & 96 \\
\hline Total & 40324 & 681 & 21406 & - & 382.1 & 56.02 & 511 \\
\hline California & 7893 & 560 & 3419 & $19 \%$ & 33.9 & 100.86 & 52 \\
\hline
\end{tabular}

\footnotetext{
${ }^{4}$ This web site is maintained by Christian Zimmermann at UQAM. It gives the list of "Economics Departments, Institutes and Research Centers in the World". http://netec.mcc.ac.uk/EDIRC
} 
table from which a contrasted image appears. On one hand, there are not much differences between countries when we look for instance at the mean number of papers per author (1.94 for Europe and 2.31 for California) or at the proportion of foreign co-authors or at the number of journals involved. On the other hand, there is a huge variation of the proportion of active authors in the total population (see column 7). In continental Europe, a productive country is a small country of Northern Europe, whereas in the whole Europe, the UK has a clear dominant position. California is slightly below the UK. Large countries have a fairly stable ratio of departments per million of inhabitants (1.2) except the UK (1.6) and California (1.7) which have more. For small countries, there is a huge variance in the number of departments. Finland and Sweden have comparatively many institutions, whilst the Netherlands has very few.

\subsection{Contrasting publication habits}

If a rather large country seems to use most of the journals referenced in the JEL database, most of its production is concentrated in few journals. More precisely, a large country tends to concentrate $50 \%$ of its articles in $10 \%$ of the journals it uses. For some countries like France, more than $50 \%$ of the articles are published in national journals. We need some definitions in order to be able to point out the widely used journals and to try to define what is a national journal.

Definition 3 A journal is said to be a major publication outlet for a country if in the distribution of articles per journal for that given country, this journal is above the median.

Definition 4 The "major" production of a country is constituted by the articles published in the major publication outlets of this country.

In these definitions, major has a pure quantitative meaning and is not related to any notion of quality. In order to illustrate these notions, we give in Table 5 the list of the major publication outlets for France.

Table 5: Major publication outlets for the 5118 articles published by France

\begin{tabular}{l|c|ccc}
\hline \hline Journal & $v(p)$ & articles & $\begin{array}{c}\text { cumulative } \\
\text { articles }\end{array}$ & $\begin{array}{c}\text { cumulative } \\
\text { percentage }\end{array}$ \\
\hline Revue-Economique & 2 & 575 & 575 & 0.11 \\
Economies-et-Societes & 1 & 538 & 1113 & 0.22 \\
Revue-d'Economie-Politique & 2 & 268 & 1381 & 0.27 \\
Annales-d'Economie-et-de-Statistique & 4 & 188 & 1569 & 0.31 \\
Revue-d'Economie-Industrielle & 1 & 166 & 1735 & 0.34 \\
Economie-Appliquee & 1 & 148 & 1883 & 0.37 \\
European-Economic-Review & 6 & 138 & 2021 & 0.39 \\
Revue-d'Economie-Regionale-et-Urbaine & 1 & 120 & 2141 & 0.42 \\
Economics-Letters & 6 & 96 & 2237 & 0.44 \\
Economie-et-Prevision & 1 & 94 & 2331 & 0.46 \\
Recherches-Economiques-de-Louvain & 3 & 87 & 2418 & 0.47 \\
Economie-Internationale & 1 & 71 & 2489 & 0.49 \\
Revue-de-L'OFCE & 1 & 64 & 2553 & 0.50 \\
Journal-of-Economic-Theory & 10 & 64 & 2617 & 0.51 \\
\hline
\end{tabular}

The language of the publication is of some help to determine what is a national journal, but some national journals in non-English speaking countries are now published in English. We would say first that a national journal receives a very significant amount of the research produced in its country. The American Economic Review and the Economic Journal are national journals in this 
respect. We must complete the definition by specifying that it does not play the same role for other countries. In our sample, the AER is a major publication outlet also for the Netherlands, Norway, Sweden and the UK. The Economic Journal plays a similar role for Austria, California, Denmark, Ireland, the Netherlands and Sweden. We propose the following definition:

Definition 5 A national journal for country $i$ is a major publication outlet for authors from this country but not for authors from any other country, except possibly from a neighbouring country using the same language.

We arrive at a list of 93 national journals (plus the Federal Reserve Bank of San Francisco Economic Review for California ). The JEL coverage of national journals may be far from complete for small countries, but seems accurate for large countries. None of these 93 journals enters our list of 69 top journals except one for the UK (Economica). For most of them $v(p)=1$.

Table 6: Publication characteristics

\begin{tabular}{l|cc|cc|cc}
\hline \hline Country & Journals & Major & \multicolumn{4}{|c}{ Decomposition of Major outlets } \\
& used & outlets & Top & Articles & National & Articles \\
\hline Austria & 247 & 39 & 11 & $24 \%$ & 1 & $6 \%$ \\
Belgium & 298 & 45 & 18 & $32 \%$ & 3 & $26 \%$ \\
Denmark & 253 & 28 & 11 & $29 \%$ & 1 & $30 \%$ \\
Finland & 174 & 12 & 4 & $17 \%$ & 2 & $53 \%$ \\
Greece & 245 & 32 & 3 & $6 \%$ & 6 & $25 \%$ \\
Ireland & 143 & 12 & 2 & $8 \%$ & 2 & $63 \%$ \\
Nethlds & 415 & 46 & 20 & $41 \%$ & 1 & $8 \%$ \\
Norway & 233 & 30 & 10 & $37 \%$ & 2 & $13 \%$ \\
Portugal & 117 & 18 & 9 & $39 \%$ & 1 & $27 \%$ \\
Sweden & 304 & 31 & 9 & $30 \%$ & 2 & $15 \%$ \\
\hline France & 398 & 13 & 3 & $11 \%$ & 10 & $85 \%$ \\
Germany & 406 & 22 & 5 & $11 \%$ & 11 & $66 \%$ \\
Italy & 355 & 24 & 3 & $7 \%$ & 17 & $81 \%$ \\
Spain & 307 & 16 & 7 & $23 \%$ & 7 & $67 \%$ \\
UK & 613 & 51 & 9 & $20 \%$ & 27 & $40 \%$ \\
\hline Total & 681 & 247 & 47 & $17 \%$ & 93 & $40 \%$ \\
\hline California & 560 & 64 & 36 & $66 \%$ & 1 & $2 \%$ \\
\hline Top jor
\end{tabular}

Top journals are journals receiving a grade greater than 5 in our ranking.

If we exclude Finland, Greece and Ireland, small countries publish a greater proportion of their major production in top journals than large European countries do, including the UK (see Table 6, column 5). The UK is the leading European country. But there is a mass effect as only $20 \%$ of its "major production" comes out in top journals while $40 \%$ of it comes out in its numerous national journals. Netherlands is the European country which has the greatest percentage of articles in top journals.

There is a group of three journals of general coverage which are used by most European countries and represent $45 \%$ of the major production: Economics Letters, European Economic Review and Economic Journal by decreasing order of quantitative importance. We should especially note the success of the European Economic Review which managed, after the creation of the European Economic Association, to become a leading European journal playing a federative role.

The European situation is in contrast with California that publishes $66 \%$ of its major production in 36 top journals, a figure much higher than any European country of our sample. With 4 major exceptions $^{5}$, California uses basically all the major top outlets used by European countries (including

\footnotetext{
${ }^{5}$ Scandinavian Journal of Economics, Journal of Applied Econometrics, International Journal of Game Theory and Journal of Health Economics
} 
the European Economic Review) plus some others that European countries do not use: American Journal of Agricultural Economics, Journal of Finance, Journal of Economic Perspectives, Journal of Political Economy, Quarterly Journal of Economics, Review of Economics and Statistics, Journal of Economic History, are the most important examples of the latter. California is also a great user of Econometrica and of the Review of Economic Studies, contrary to most European countries.

\section{Measuring the scientific production of an institution}

There is probably widespread agreement that institutions should be ranked according to the aggregate score of their members. However, this aggregation has to rely on a precise definition of what constitutes an academic research institution. For this purpose, it may be helpful to keep in mind the paradigm of the student who tries to find the best location to write his $\mathrm{PhD}$ dissertation.

\subsection{Definitions and implied aggregation formulae}

We shall give two opposite definitions of what is an academic research institution. The first definition insists on short term capacity. The second one relies more on past reputation.

Definition 6 An academic research institution is defined at time $t$ as a collection of individuals having a research and a teaching activity in the field of economics. These individuals have a common physical location. They acknowledge their current affiliation in their scientific publications. They constitute the collective human capital of the institution.

This definition insists on current (not past) affiliations. It is in a way a short term definition, because it does not take into account the history of the institution. Once an individual leaves his institution, he leaves it with all his publication stock. When a new member arrives, the institution is credited with all his past scientific achievements. This definition is of primary interest for a $\mathrm{PhD}$ student because it aims at measuring the current human capital of the institution. It is the reason why it also insists on common location. Common location implies that research institutes like the Tinbergen Institute located both in Amsterdam and Rotterdam have to be split and that its achievements have to be divided between the host institutions, Erasmus University Rotterdam, University van Amsterdam and Free University of Amsterdam. The Tinbergen Institute is seen as a research network and thus cannot not be ranked. Other exemples are CEPR for Europe, CNRS for France and other national research institution which have many separate locations.

The score of institution $k$ measuring its available human capital is thus defined by

$$
s d_{k}=\sum_{i=1}^{n} \mathbb{I}\left(i \in \Theta_{k, t}\right) \sum_{j=0}^{m} s_{i, t-j}
$$

where $\Theta_{k, t}$ is the set of members affiliated to institution $k$ at time $t$. Index $i$ covers all the $n$ economists of a country and index $j$ corresponds to the $m$ year span. There is no double counting.

Formula (3) does not however correspond to the usual practice where affiliation at the time of publication is used. For instance, a visitor usually indicates the temporary affiliation of the hosting institution on the papers he has written during his visit. So another definition is needed which is more related to intellectual ownership.

Definition 7 An academic research institution is a "moral person" having the intellectual ownership of all the present and past research hosted in its walls.

This definition is certainly the preferred one for a dean writing a report on past research and past achievements when he has to ask his government for money. It is a legalistic definition. The corresponding score of institution $k$ is given by

$$
\widetilde{s d}_{k}=\sum_{i=1}^{n} \sum_{j=0}^{m} \mathbb{I}\left(i \in \Theta_{k, t-j}\right) s_{i, t-j}
$$


where $\Theta_{k, t-j}$ is the set of members affiliated to institution $k$ at time of publication. This measure can be used to assess the productivity of the money invested by the institutions in the past.

\section{Remarks:}

- Bauwens (1999) implicitly uses the legalist definition in his yearly ranking of Belgian economists and Belgian academic institutions. He took $m=4$, but considers two periods 1992-1996 and 1993-1997. His institution rankings do not vary much, but his ranking of individuals has a large volatility.

- To our knowledge, Cribari-Neto et al. (1999) are the only authors to present rankings obtained according to the two definitions. But they do not interpret the economic or legal meaning of these two rankings.

- The yearly ranking produced by CentER at Tilburg University is based only on the current year publications. For this ranking $m=1$ and the two definitions become identical.

- Information about the affiliation at the time of publication is directly given by the JEL database. It appears to be much more difficult to get the list of the members of an institution at time $t$. We cannot see a simple way to reconstruct it from the data contained in the JEL database.

\subsection{The need for a partition}

Ranking the institutions of a country is equivalent to achieve at the complete ordering of the set $\Omega_{t}$ representing all the authors of that country. Institutions have to form a partition of that set.

Assusmption 1 For a given $t, \Theta_{k, t}, k=1, q$ operates a partition of $\Omega_{t}$.

This condition is necessary, but however not sufficient in order to produce meaningful rankings. There is a large diversity existing among the institutions producing academic research and which appear in the JEL CD-ROM. We have universities, colleges, research groups. We ave explained why it was necessary to leave aside what can be considered as networks like CNRS in France or FNRS in Belgium. We must explicit a hierarchy and distinguish between major and secondary affiliations. For instance in the UK, a college has to be considered as a subgroup of a university like Nuffield for Oxford. Nuffield cannot be compared to Cambridge, but Oxford can be. We have the same distinction in continental Europe with research groups like CORE which has to be included in Catholic University of Louvain, GREMAQ in Toulouse University and so on. We had thus to correct and complete the affiliation data in order to achieve coherency.

The problem of comparability is complicated when a person has several affiliations. For instance Jean Tirole declares most of the time three affiliations: Toulouse, ENPC and MIT; and most of the time three secondary affiliations: IDEI, GREMAQ and CERAS. A strict aggregation procedure would require this author to be split in three pieces, one for each town and the Toulouse part in its turn to be split in two, one for each research center (GREMAQ and IDEI). This is clearly infeasible as we have no information to determine the size of each part. We have finally considered that there are three fictitious authors, each full time in each major institution. And we discarded one of the secondary affiliations (IDEI was not ranked). Applying this type of solution to all cases renders institutions comparable, but of course may bias the ranking.

\subsection{The need for a minimum level of publication}

A PhD student, when looking for a superviser, looks for a person having a certain level of intellectual prowess or fame compared to his colleagues. So we have to define a minimum level below which a person is not thought of being able to supervise a $\mathrm{PhD}$ student. We define this level as a minimum 
level of publication over the 10 year period of our sample. One paper published in a top journal with one coauthor (or its equivalent) seems reasonable. This makes $z=10 / \sqrt{2}=7.07$. The total score $x_{i}$ of an author is defined by

$$
x_{i}=\sum_{t=1}^{m} s_{i, t}
$$

with $m=10$ in our case. To achieve a final ranking, we do not credit a department for all its publications, but only for the publications which were written by authors verifying the condition $x_{i}>z$. The list of eligible authors is built up country by country, independently of their affiliations, provided these affiliations are situated inside the same country. If an author has not migrated between two European countries, this is the human capital view. Then the publications of this restricted list of authors are allocated to the departments according to the rule of the affiliation at the time of publication. This is the copyright view.

\section{Statistical inference on department ranking}

The ideal economics department can be defined as a department with a large number of authors having a score greater than $z$ as measured by $\sum \mathbb{I}\left(x_{i}>z\right){ }^{6}$ The ideal economics department can also be defined as a department where the productivity gap $\sum\left(x_{i}-z\right) \mathbf{I}\left(x_{i}>z\right)$ is large. Both of these notions are related to a variant of the concept of stochastic dominance. Lubrano and Protopopescu (2002) have developed the mathematics related to stochastic dominance for comparing the academic systems of two countries. We examine in this section how this framework can be adapted to the ranking of departments.

\subsection{Inference and test}

Our viewpoint is that the score of a department should be considered as a random variable. When we observe the scores of two departments (hereafter named $A$ and $B$ ), we may then wonder if the difference between these scores is significant in the usual statistical sense. An hypothesis test should be performed to answer this question.

The score of a department is the sum of the scores of the authors affiliated to it, provided that they have a personal score greater than $z$. Let $X_{A i}$ be a random variable denoting the score of individual $i$ in department $A$. Let $N_{A}$ denote the number of authors affiliated to $A$. We assume that $X_{A i}$, for $i=1, \ldots, N_{A}$, are mutually independent in probability and identically distributed according to a distribution with mean $\mu_{A}$ and variance $\sigma_{A}^{2}$. We make the same assumptions for $B$. We also assume that the score of an individual in $A$ is independent of the score of any individual in $B$. In short,

$$
\begin{aligned}
& X_{A i} \sim \text { I.I.D. }\left(\mu_{A}, \sigma_{A}^{2}\right), i=1, \ldots, N_{A}, \\
& X_{B j} \sim \text { I.I.D. }\left(\mu_{B}, \sigma_{B}^{2}\right), j=1, \ldots, N_{B}, \\
& X_{A i} \text { independent of } X_{B j}, \forall i, \forall j .
\end{aligned}
$$

These assumptions are not totally realistic. The performances of authors in a given department are probably positively correlated, because of collaborations (leading to co-authorship of papers) but we think that the correlation is small and can be neglected, and anyway, we don't have the possibility to estimate it. The same comment applies to the scores of individuals in different departments (in case of double affiliation of an individual, there is clearly a lack of independence, but this phenomenon is not too much widespread).

The precise type of the distribution is not important. What is important is that it can be described by its mean and variance, which covers many non-symmetric two parameter distributions. We only need that a central limit theorem applies, such that the mean score of a department (or its total score) can be approximated by a normal distribution in large samples. Thus, we assume that

\footnotetext{
${ }^{6} \mathbf{I I}($.$) is the Dirac function.$
} 
$N_{A}$ and $N_{B}$ are not very small. This is true in our data, where in most departments the number of authors above the threshold is not smaller than 30 (see Tables 6 and 7, where the number of authors is given).

The total score of $A$ is estimated by

$$
T S_{A}=\sum_{i=1}^{N_{A}} x_{A i}
$$

and its variance by

$$
s_{A}^{2}=\sum_{i=1}^{N_{A}}\left(x_{A i}-N_{A}^{-1} T S_{A}\right)^{2}
$$

with similar definitions for $T S_{B}$ and $s_{B}^{2}$. To test the equality of the total scores of $A$ and $B$, we can use the well-known result that under the previous assumptions, asymptotically,

$$
t=\frac{T S_{A}-T S_{B}}{\sqrt{s_{A}^{2}+s_{B}^{2}}} \sim N(0,1)
$$

The 5 percent critical value is 1.96 and the 10 percent one is 1.66 for a bilateral test. A law of large numbers can be invoked for the consistency of the estimators of the variances.

It should be noticed that the null hypothesis is $N_{A} \mu_{A}=N_{B} \mu_{B}$ and not $\mu_{A}=\mu_{B}$. The two hypotheses differ to the extent that the departments have different sizes. If for example, $A$ has twice the size of $B$, we test $\mu_{A}=\mu_{B} / 2$ : an author from $B$ has to be twice as productive as an author from $A$ for the two departments to be equivalent.

Finally we should point out that we neglect the randomness of the number of authors in each department, that is, we take $N_{A}$ and $N_{B}$ as given, although these numbers are obviously not deterministic and subject to measurement error. Taking this feature into account would increase the variance of the total scores. This variance would also be increased by the positive correlation between the scores of individuals. Therefore, the test statistic proposed above for the difference between the total scores is probably too large, leading to over-rejections of equality at a given nominal level of significance. If the test statistic is close to the critical value, we have to be careful in our inference, whereas if it is very small or very large, we can clearly conclude in the usual way.

\subsection{A simple class of indices}

Let us now introduce the minimum level of production $z$ and let us suppose that the data reflect the human capital view for the definition of a department. This means that once an author belongs to a department, his total score and his score attributed to that department coincide. The total score of a department, when authors below $z$ are excluded can be defined as

$$
T S_{A}(z)=\sum_{i=1}^{N_{A}}\left(x_{i}-z\right) \mathbb{I}\left(x_{i}>z\right)
$$

Let us now suppose that $X$ is a continuous random variable with density $f(x)$. We can write

$$
P_{A}^{\alpha}(z)=N_{A} \int_{z}^{\infty}(x-z)^{\alpha} f(x) d x
$$

where $\alpha$ is a positive parameter. For $\alpha=1,(9)$ and (10) represent the same notion. But we can also note that $P_{A}^{\alpha}(z)$ is very much related to the class of decomposable poverty indices introduced by Foster, Greer and Thorbecke (1984). Moreover, when $z$ varies between 0 and $\infty, P_{A}^{\alpha}(z)$ becomes a measure of stochastic dominance at the order $\alpha+1$ as proved in Lubrano and Protopospescu (2003). Consequently, we can propose the following definition

Definition 8 Department $A$ is said to dominate department $B$ according to the index $P^{\alpha}(z)$ if $P_{A}^{\alpha}(z) \geq P_{B}^{\alpha}(z)$ for a given level $z$ of academic production. 
The application of this definition can lead to different rankings according to the value chosen for $\alpha$. If $\alpha=0$, we are ranking departments according to the number of active academics having a production greater than $z$. This is a head count measure which is invariant to the degree of activity of productive academics, provided they produce above the minimum level $z$. If $\alpha=1$, the ranking takes into account the cumulated production of authors having a production greater than $z$. We feel that the notions of stochastic dominance at the order one and two are not far away. However, we consider indices as $z$ is fixed. So rankings will very much depend on the value chosen for $z$. We have justified previously a rather low value of 7.07. If $z$ were too high, departments would be ranked only according to the score of their most productive members.

We have discussed the fact that it is rather difficult to apply the human capital definition of a department and that the copyright view implied by affiliation at the time of publication is far easier. With this definition, it becomes much more difficult to use the index $P_{A}^{\alpha}(z)$ as $z$ is meaningful only if $x$ reflect the total production of an author. We proceed as follows. We have observed for each author $i$ his production $s_{i, t}$ for year $t$, assuming that he keeps the same affiliation over the year $t$. We can cumulate over $t$ the production of each author independently of his affiliations and then eliminate from the database authors having a score lower than $z$. On the remaining data, we finally can compute $P_{A}^{\alpha}(z)$ imposing $z=0$ as less productive authors have already been discarded.

\section{Ranking economics departments in Europe}

We have identified 511 economics departments in Europe using official data. However, only 363 of them are visible on the JEL database and only 166 have more than 10 active members with a personal score greater than 7.07 .

\subsection{Using the full list of journals}

This ranking, given in Table 7, is not immune to the equivalence effect. We have limited the listing to the first 100 departments.

Table 7: European ranking based on the full list of journals

\begin{tabular}{|c|c|c|c|c|c|}
\hline Rank & Institution & total score & std. dev. & authors & papers \\
\hline 1 & LSE & 2637.33 & $(256.97)$ & 150 & 726 \\
\hline 2 & Tilburg U & 2433.20 & $(331.86)$ & 108 & 618 \\
\hline \multirow[t]{3}{*}{3} & U Oxford & 2074.31 & (181.48) & 119 & 641 \\
\hline & Nuffield College & 660.66 & $(117.86)$ & 31 & 163 \\
\hline & Institute of Econ and Stat & 225.41 & $(60.21)$ & 19 & 61 \\
\hline \multirow[t]{2}{*}{4} & U Cambridge & 1919.50 & $(200.46)$ & 101 & 660 \\
\hline & Trinity College & 258.33 & (139.98) & 7 & 70 \\
\hline 5 & Erasmus U Rotterdam & 1692.40 & $(115.06)$ & 92 & 545 \\
\hline \multirow[t]{3}{*}{6} & Catholic U Louvain & 1611.94 & $(257.60)$ & 73 & 489 \\
\hline & CORE & 1195.94 & $(239.39)$ & 48 & 345 \\
\hline & IRES & 184.46 & $(68.71)$ & 10 & 68 \\
\hline 7 & U Amsterdam & 1435.42 & (183.19) & 68 & 429 \\
\hline 8 & U Warwick & 1378.41 & $(124.10)$ & 70 & 430 \\
\hline \multirow[t]{2}{*}{9} & U Toulouse & 1331.90 & $(306.18)$ & 43 & 352 \\
\hline & GREMAQ & 1123.06 & $(257.75)$ & 30 & 293 \\
\hline \multirow[t]{3}{*}{10} & U Paris I & 1229.64 & $(117.92)$ & 79 & 438 \\
\hline & EUREQUA & 551.36 & $(82.40)$ & 39 & 204 \\
\hline & CERMSEM & 172.17 & $(21.26)$ & 10 & 35 \\
\hline \multirow[t]{2}{*}{11} & U College London & 1224.10 & $(204.36)$ & 62 & 364 \\
\hline & IFS & 1093.82 & $(156.86)$ & 48 & 317 \\
\hline
\end{tabular}




\begin{tabular}{|c|c|c|c|c|c|}
\hline Rank & Institution & total score & std. dev. & authors & papers \\
\hline 12 & U Nottingham & 1169.51 & $(163.70)$ & 43 & 412 \\
\hline 13 & U York & 1102.71 & $(144.75)$ & 53 & 343 \\
\hline 14 & Stockholm School of Econ & 1066.09 & $(145.35)$ & 56 & 310 \\
\hline 15 & Maastricht $\mathrm{U}$ & 1064.94 & (226.13) & 60 & 350 \\
\hline \multirow[t]{2}{*}{16} & INSEE, Paris & 1004.77 & $(175.84)$ & 59 & 314 \\
\hline & CREST & 899.68 & $(161.06)$ & 46 & 272 \\
\hline 17 & U Essex & 988.45 & $(143.02)$ & 37 & 234 \\
\hline 18 & Stockholm U & 935.42 & $(111.78)$ & 50 & 227 \\
\hline \multirow[t]{2}{*}{19} & U Autonoma Barcelona & 932.92 & $(193.32)$ & 46 & 238 \\
\hline & IAE & 268.80 & $(48.65)$ & 20 & 69 \\
\hline 20 & U Bonn & 900.15 & $(226.65)$ & 57 & 218 \\
\hline 21 & CERAS, Paris & 885.94 & $(229.69)$ & 14 & 209 \\
\hline 22 & London Business School & 883.44 & $(100.50)$ & 53 & 281 \\
\hline 24 & Free $U$ of Amsterdam & 852.47 & $(146.16)$ & 47 & 319 \\
\hline 24 & U Manchester & 844.95 & $(60.38)$ & 72 & 305 \\
\hline \multirow[t]{2}{*}{25} & Free U Brussels & 844.28 & $(156.34)$ & 33 & 228 \\
\hline & ECARES & 617.53 & $(86.84)$ & 19 & 140 \\
\hline 26 & U Copenhagen & 824.28 & $(151.62)$ & 41 & 211 \\
\hline 27 & Catholic U Leuven & 800.26 & $(140.50)$ & 41 & 317 \\
\hline \multirow[t]{2}{*}{28} & EHESS-PARIS & 792.40 & $(163.36)$ & 35 & 209 \\
\hline & DELTA & 695.23 & $(168.33)$ & 27 & 171 \\
\hline 29 & U Groningen & 780.62 & $(98.24)$ & 44 & 301 \\
\hline \multirow[t]{2}{*}{30} & U Aix-Marseille & 752.47 & $(155.06)$ & 29 & 219 \\
\hline & GREQAM & 716.42 & (150.58) & 26 & 202 \\
\hline 31 & U Pompeu Fabra & 744.36 & $(103.20)$ & 40 & 182 \\
\hline 32 & U Carlos III & 727.77 & $(218.80)$ & 41 & 178 \\
\hline 33 & U Munich & 703.57 & $(123.63)$ & 33 & 230 \\
\hline 34 & U Reading & 701.64 & $(75.64)$ & 43 & 275 \\
\hline 35 & CEPREMAP, Paris & 694.55 & $(137.35)$ & 30 & 238 \\
\hline 36 & U Southampton & 670.62 & $(69.20)$ & 49 & 181 \\
\hline 37 & U Oslo & 669.56 & $(134.11)$ & 38 & 174 \\
\hline 38 & National Institute of Econ (UK) & 667.35 & $(150.62)$ & 34 & 353 \\
\hline 39 & Birkbeck College & 659.92 & $(95.95)$ & 34 & 201 \\
\hline 40 & U E Anglia & 645.12 & (112.38) & 34 & 228 \\
\hline 41 & U Newcastle & 642.29 & $(62.90)$ & 44 & 228 \\
\hline 42 & U Vienna & 618.06 & $(99.89)$ & 37 & 169 \\
\hline 43 & U Bristol & 612.43 & $(75.61)$ & 41 & 152 \\
\hline 44 & U Aarhus & 599.74 & $(129.79)$ & 28 & 177 \\
\hline 45 & U Mannheim & 588.47 & $(144.57)$ & 38 & 195 \\
\hline 46 & Uppsala U & 574.61 & (106.68) & 39 & 177 \\
\hline 47 & U Strathclyde (UK) & 570.05 & $(101.57)$ & 36 & 213 \\
\hline 48 & U Glasgow & 563.21 & $(72.04)$ & 44 & 174 \\
\hline 49 & U Exeter & 555.52 & $(85.13)$ & 25 & 160 \\
\hline 50 & Norwegian School of Econ & 514.56 & $(97.05)$ & 33 & 163 \\
\hline 51 & INSEAD, Paris & 508.03 & (113.18) & 22 & 140 \\
\hline 52 & U Birmingham & 479.83 & $(67.16)$ & 33 & 162 \\
\hline 53 & U Bologna & 476.61 & $(108.54)$ & 25 & 178 \\
\hline 54 & European U Institute (Italy) & 471.57 & $(123.68)$ & 29 & 121 \\
\hline \multirow[t]{2}{*}{55} & U Bocconi & 460.79 & $(62.39)$ & 38 & 165 \\
\hline & IGIER & 209.44 & (41.91) & 18 & 57 \\
\hline
\end{tabular}




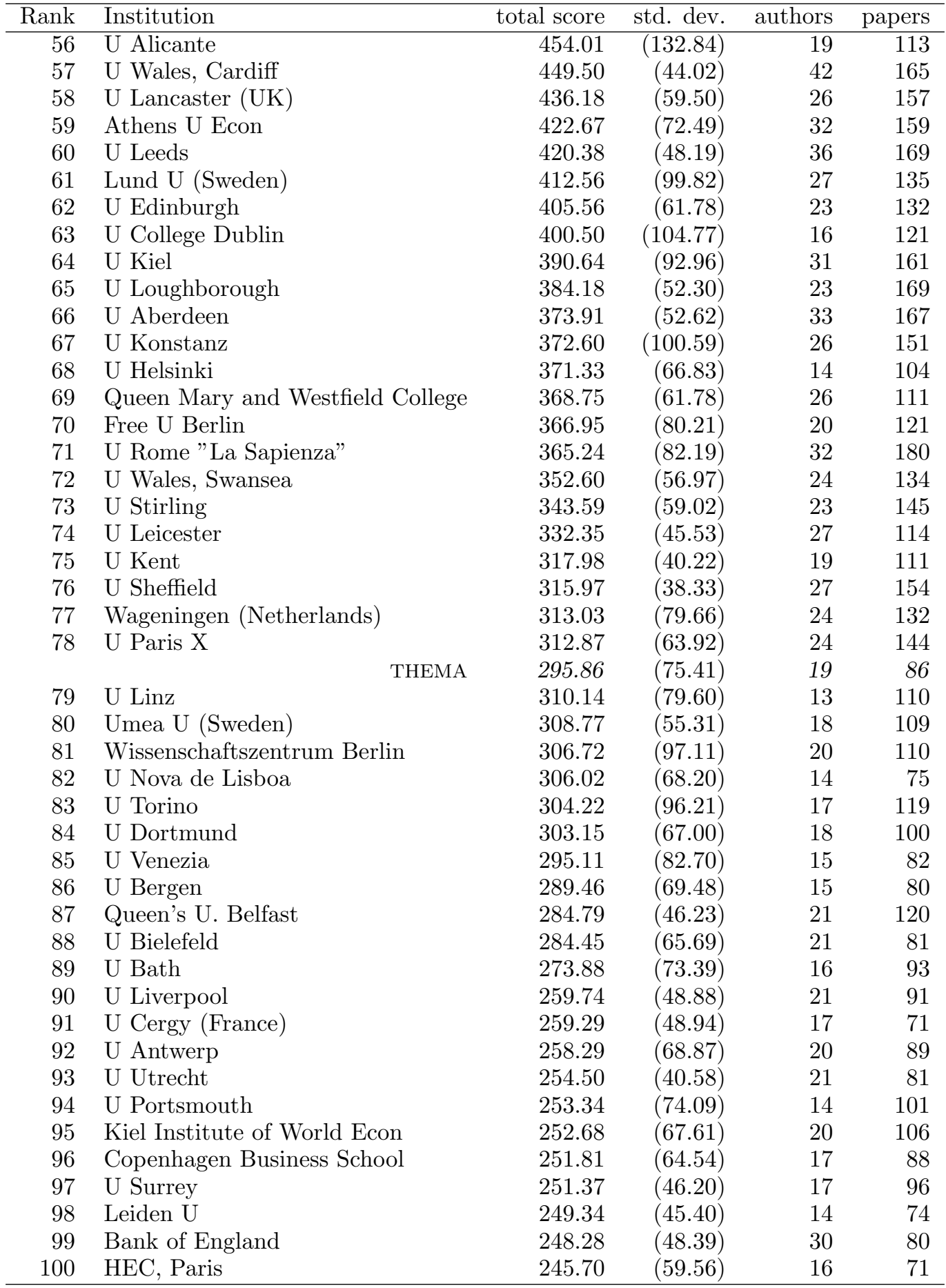

Column 1 indicates the rank of a department and column 3 its total score. Column 4 gives an indication about the uncertainty attached to this ranking as it is the standard deviation of the total score of each department. Column 5 gives another indication which could be used to produce another ranking as it represents the number of active members. It conforts the intuitive idea that a good department has a critical mass. We do not report the mean score per active member. It seems to be roughly independent of the global ranking which seems intuitively reasonable. As we choose a copyright definition for a department, good $\mathrm{PhD}$ students who were one time members of a department are included to arrive at that ranking. A good department has many good $\mathrm{PhD}$ 
students but these get a low score over the 10 years because they do not keep the affiliation for long. Using the mean score for ranking would penalize enormously those good departments.

Let us now consider the first 20 departments and test if they can be considered as equivalent using the statistic in (8). We get the $20 \times 20$ Table 8 of results. Significant values at the $10 \%$ level are indicated in bold faces. It appears from this table that for instance LSE and Tilburg are

Table 8: t statistics for the top 20 european departments

\begin{tabular}{|c|c|c|c|c|c|c|c|c|c|c|}
\hline & Lse & Til & Oxf & Cam & Ers & Lou & Ams & Var & Tou & Par \\
\hline Lse & 0.00 & 0.58 & 1.80 & 2.21 & 2.82 & 3.10 & 3.94 & 4.43 & 3.28 & 4.82 \\
\hline Til & 58 & 00 & 1.19 & 1.64 & 2.29 & 2.57 & 3.41 & 3.90 & 2.83 & 4.32 \\
\hline Oxf & 80 & -1.19 & 0.00 & 57 & 1.36 & 1.67 & 2.61 & 19 & 2.10 & .70 \\
\hline Cam & 21 & -1.64 & -0.57 & 0.00 & 0.77 & 1.06 & 1.87 & 2.31 & 1.61 & .83 \\
\hline Ers & 82 & -2.29 & -1.36 & -0.77 & 0.00 & 0.27 & 0.95 & .27 & 0.97 & .81 \\
\hline Lou & 10 & -2.57 & -1.67 & -1.06 & -0.27 & 0.00 & 0.66 & 0.96 & 0.76 & 1.52 \\
\hline Ams & 94 & -3.41 & -2.61 & -1.87 & -0.95 & -0.66 & 0.00 & 0.28 & 0.30 & 0.95 \\
\hline War & 43 & .90 & -3.19 & -2.31 & -1.27 & -0.96 & -0.28 & 0.00 & 0.14 & 0.80 \\
\hline Tou & 28 & -2.83 & -2.10 & -1.61 & -0.97 & -0.76 & -0.30 & -0.14 & 0.00 & 0.31 \\
\hline Par & 82 & -4.32 & -3.70 & -2.83 & -1.81 & -1.52 & -0.95 & -0.80 & -0.31 & 0.00 \\
\hline UCL & 32 & -3.83 & -3.13 & -2.44 & -1.58 & -1.33 & -0.81 & -0.65 & -0.29 & -0.02 \\
\hline Not & 84 & -4.35 & -3.73 & -2.92 & -1.94 & -1.68 & -1.15 & -1.03 & -0.47 & -0.28 \\
\hline Yor & 23 & -4.74 & -4.21 & -3.32 & -2.28 & -2.01 & -1.52 & -1.46 & -0.68 & -0.64 \\
\hline StoS & .29 & -4.81 & -4.30 & -3.42 & -2.39 & -2.12 & -1.65 & -1.61 & -0.78 & -0.80 \\
\hline Maа & 38 & -4.90 & -4.41 & -3.50 & -2.44 & -2.17 & -1.71 & -1.68 & -0.80 & -0.83 \\
\hline Ins & 50 & -5.03 & -4.56 & -3.67 & -2.62 & -2.36 & & -1.93 & -0.96 & -1.10 \\
\hline Esx & 64 & -5.17 & -4.74 & -3.81 & -2.74 & -2.48 & -2 & -2.09 & -1.02 & -1.22 \\
\hline StoU & 47 & -5.01 & -4.51 & -3.69 & -2.72 & -2.47 & & -2.06 & -1.13 & -1.31 \\
\hline Bar & 06 & -5.61 & -5.32 & -4.28 & -3.11 & -2.84 & -2 & -2.65 & -1.22 & -1.64 \\
\hline \multirow[t]{2}{*}{ Bon } & -6.41 & -5.97 & -5.85 & -4.68 & -3.41 & -3.14 & -2.86 & -3.17 & -1.36 & -2.00 \\
\hline & UCL & Not & Yor & StoS & Maa & Ins & Esx & StoU & Bar & Bon \\
\hline Lse & 4.32 & 4.84 & 5.23 & 5.29 & 5.3 & 5.50 & 5.64 & 5.47 & 6.06 & .41 \\
\hline Til & & 4.35 & 4.74 & 4.81 & 4.90 & 5.03 & 5.17 & 5.01 & 5.61 & 5.97 \\
\hline $\mathrm{O}$ & & 3.73 & 4.21 & 4.30 & 4.41 & 4.56 & 4. & 4.51 & 5.32 & 5.85 \\
\hline Cam & 4 & 2.92 & 3.32 & 3.42 & 3.50 & 3.67 & 3.81 & 3.69 & 4.28 & 4.68 \\
\hline E & & 1. & 2.28 & 2.39 & 2.44 & 2.62 & 2.74 & 2.72 & 3.11 & 3.41 \\
\hline & & 8 & 2.01 & 2.12 & 2.17 & 2.36 & 2.48 & 2.47 & 2.84 & 3.14 \\
\hline & & & 1.52 & 1.65 & 17 & 1.93 & 6 & 2.07 & 2.49 & .86 \\
\hline & & & 6 & 61 & & 93 & 9 & 6 & 2.65 & .17 \\
\hline & & & & & & 96 & & 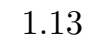 & .22 & 1.36 \\
\hline & & & & & & 10 & & 1 & 1.64 & 2.00 \\
\hline & & & & & & 0.87 & & & 1.24 & 1.46 \\
\hline & & & & & & 0.75 & & 8 & 1.1 & 1.47 \\
\hline & & & & & & 0.47 & & 74 & 0.92 & 1.21 \\
\hline & & & & & & 0.29 & & 6 & 0.70 & 0.96 \\
\hline & & & & & & 0.29 & & 7 & 0.73 & .99 \\
\hline In & & & & -0.29 & -0.29 & 0.00 & 0.08 & 0.30 & 0.38 & 0.60 \\
\hline & & & & & & -0.08 & & 0.24 & 0.31 & 0.53 \\
\hline & & & & & -0.57 & -0.30 & -0.24 & 0.00 & 0.01 & 0.18 \\
\hline $\mathrm{Ba}$ & & & -0.92 & -0.70 & -0.73 & -0.38 & -0.31 & -0.01 & 0.00 & 0.23 \\
\hline Bon & -1.46 & -1.47 & -1.21 & -0.96 & -0.99 & -0.60 & -0.53 & -0.18 & -0.23 & 0.00 \\
\hline
\end{tabular}

Bold numbers indicate that the test is significant at the $10 \%$ level.

not statistically different. The same for Oxford, Cambridge and Erasmus. It does not seem to be 
possible to justify a strict order on a statistical basis for the last 10 departments of the list at the $10 \%$ level. In particular if Toulouse is dominated by LSE, Tilburg and Oxford, it does not manage to be statistically different from its followers. Toulouse is especially difficult to rank because it is comparatively a small department with its 43 active members compared to the 70 of Warwick which has a similar total score and because its standard deviation of 306.18 is large compared to the 124.10 of Warwick.

This uncertainty in the ranking is well apparent if we rank departments according to the index $P^{\alpha}(z)$ using various values for $\alpha$. With $\alpha=0$, we rank departments according to their size. LSE

Table 9: Ranking departments according to $P^{\alpha}(z)$

\begin{tabular}{cc|cc|cc}
\hline \multicolumn{2}{c}{$\alpha=0$} & \multicolumn{2}{c}{$\alpha=1$} & \multicolumn{2}{c}{$\alpha=2$} \\
\hline Lse & 150.00 & Lse & 2637.34 & Tou & 366.06 \\
Oxf & 119.00 & Til & 2433.27 & Til & 336.32 \\
Til & 108.00 & Oxf & 2074.31 & Lse & 334.81 \\
Cam & 101.00 & Cam & 1919.53 & Lou & 281.56 \\
Ers & 92.00 & Ers & 1692.40 & Ers & 278.20 \\
Par & 79.00 & Lou & 1611.94 & Cam & 276.24 \\
Lou & 73.00 & Ams & 1435.42 & Oxf & 262.28 \\
War & 70.00 & War & 1378.41 & UCL & 256.03 \\
Ams & 68.00 & Tou & 1331.90 & Not & 240.59 \\
UCL & 62.00 & Par & 1229.64 & Ams & 240.18 \\
Maa & 60.00 & UCL & 1224.10 & StoU & 220.54 \\
Ins & 59.00 & Not & 1169.51 & Esx & 214.86 \\
Bon & 57.00 & Yor & 1102.71 & Yor & 208.50 \\
StoS & 56.00 & StoS & 1066.10 & StoS & 206.74 \\
Yor & 53.00 & Maa & 1064.94 & War & 205.33 \\
StoU & 50.00 & Ins & 1004.77 & Ins & 198.91 \\
Bar & 46.00 & Esx & 988.45 & Maa & 196.68 \\
Not & 43.00 & StoU & 935.42 & Par & 196.33 \\
Tou & 43.00 & Bar & 932.92 & Bar & 179.62 \\
Esx & 37.00 & Bon & 900.15 & Bon & 147.96 \\
\hline
\end{tabular}

The square root of the statistic is indicated in the last column for scaling reasons.

is first, and Toulouse is near the end of the list of 20 . With $\alpha=1$, we get the previous ranking according to the total production. With $\alpha=2$, we rank departments according to the square of the production of each author. Toulouse is now first of the top 20 and gets a similar index as Tilburg and LSE. This way of ranking is very penalizing for Paris I.

\subsection{Using the list of top journals}

Now we try to avoid the equivalence effect. Table 10 shows that some large and heterogenous institutions are downgraded, while smaller ones keep their good ranking: LSE drops below Tilburg; Oxford and Cambridge drop below Toulouse; Paris I is now below Maastricht and roughly at the same level as Aix-Marseille; Erasmus drops below Amsterdam.

Table 10: European ranking based on the top journals in the list

\begin{tabular}{rlrrrr}
\hline Rank & Institution & total score & std. dev. & authors & papers \\
\hline 1 & Tilburg U & 1870.70 & $(199.86)$ & 83 & 538 \\
2 & LSE & 1690.35 & $(191.97)$ & 93 & 535 \\
3 & Catholic U Louvain & 1081.32 & $(145.37)$ & 52 & 403 \\
\hline
\end{tabular}




\begin{tabular}{|c|c|c|c|c|c|}
\hline Rank & Institution & total score & std. dev. & authors & papers \\
\hline & CORE & 910.52 & $(137.37)$ & 37 & 318 \\
\hline & IRES & 85.00 & $(25.36)$ & 8 & 52 \\
\hline \multirow[t]{2}{*}{4} & U Toulouse & 1032.05 & $(264.91)$ & 34 & 319 \\
\hline & GREMAQ & 889.41 & $(250.77)$ & 25 & 268 \\
\hline \multirow[t]{3}{*}{5} & U Oxford & 1011.81 & $(122.83)$ & 54 & 355 \\
\hline & Nuffield College & 485.23 & $(91.96)$ & 23 & 138 \\
\hline & Institute of Econ and Statistics & 151.04 & $(40.17)$ & 14 & 54 \\
\hline 6 & U Amsterdam & 942.29 & $(131.59)$ & 45 & 317 \\
\hline 7 & Erasmus U Rotterdam & 931.22 & $(144.41)$ & 52 & 364 \\
\hline \multirow[t]{2}{*}{8} & U Cambridge & 854.75 & $(150.15)$ & 51 & 340 \\
\hline & Trinity College & 212.53 & $(126.32)$ & 6 & 66 \\
\hline 9 & U Warwick & 796.52 & $(89.46)$ & 46 & 315 \\
\hline \multirow[t]{2}{*}{10} & U Autonoma Barcelona & 770.01 & $(97.35)$ & 37 & 214 \\
\hline & Institut d'Analisi Econ & 226.71 & (49.11) & 18 & 66 \\
\hline 11 & U Essex & 754.06 & $(118.10)$ & 33 & 225 \\
\hline \multirow[t]{2}{*}{12} & U College London & 743.91 & $(144.64)$ & 31 & 246 \\
\hline & IFS & 658.26 & (117.67) & 32 & 244 \\
\hline 13 & Stockholm U & 731.25 & $(154.50)$ & 37 & 195 \\
\hline 14 & Stockholm School of Econ & 730.97 & $(119.59)$ & 42 & 258 \\
\hline 15 & CERAS & 724.19 & $(181.22)$ & 13 & 207 \\
\hline 16 & U York & 678.12 & $(102.07)$ & 32 & 225 \\
\hline \multirow[t]{2}{*}{17} & INSEE & 647.95 & $(111.09)$ & 40 & 254 \\
\hline & CREST & 625.22 & $(106.92)$ & 35 & 240 \\
\hline 18 & U Bonn & 630.27 & $(69.69)$ & 43 & 175 \\
\hline 19 & U Copenhagen & 626.44 & $(95.43)$ & 32 & 181 \\
\hline \multirow[t]{2}{*}{20} & Free U Brussels & 601.22 & $(116.42)$ & 20 & 164 \\
\hline & ECARES & 502.50 & $(117.02)$ & 17 & 133 \\
\hline 21 & U Pompeu Fabra & 589.45 & $(81.55)$ & 35 & 157 \\
\hline \multirow[t]{2}{*}{22} & EHESS-PARIS & 588.80 & $(129.63)$ & 25 & 174 \\
\hline & DELTA & 538.80 & $(131.74)$ & 22 & 161 \\
\hline 23 & Maastricht U & 569.61 & $(86.14)$ & 33 & 215 \\
\hline 24 & U Carlos III & 560.80 & $(53.71)$ & 33 & 154 \\
\hline \multirow[t]{3}{*}{25} & U Paris I & 545.24 & $(96.42)$ & 32 & 223 \\
\hline & EUREQUA & 177.09 & $(37.07)$ & 15 & 116 \\
\hline & CERMSEM & 152.78 & $(31.41)$ & 10 & 35 \\
\hline 26 & London Business School & 521.43 & $(70.28)$ & 38 & 231 \\
\hline 27 & U Nottingham & 519.14 & $(75.31)$ & 29 & 326 \\
\hline \multirow[t]{2}{*}{28} & U Aix-Marseille & 503.95 & (124.54) & 17 & 180 \\
\hline & GREQAM & 495.09 & $(122.60)$ & 17 & 173 \\
\hline 29 & U Oslo & 491.15 & $(82.86)$ & 29 & 147 \\
\hline 30 & Free $\mathrm{U}$ of Amsterdam & 460.00 & $(78.27)$ & 28 & 229 \\
\hline 31 & U Vienna & 439.04 & $(75.53)$ & 26 & 135 \\
\hline 32 & U Southampton & 421.14 & $(59.11)$ & 30 & 113 \\
\hline 33 & Birkbeck College & 418.96 & $(70.16)$ & 25 & 161 \\
\hline 34 & U Munich & 401.53 & $(65.09)$ & 22 & 180 \\
\hline 35 & CEPREMAP & 394.14 & $(94.12)$ & 21 & 156 \\
\hline 36 & Uppsala U & 391.77 & $(67.20)$ & 27 & 144 \\
\hline 37 & U Alicante & 378.71 & $(71.27)$ & 19 & 113 \\
\hline
\end{tabular}




\begin{tabular}{rlrrrr}
\hline Rank & Institution & total score & std. dev. & authors & papers \\
\hline 38 & INSEAD & 371.84 & $(55.29)$ & 19 & 115 \\
39 & U Mannheim & 371.23 & $(57.59)$ & 29 & 174 \\
40 & U Aarhus & 370.58 & $(70.70)$ & 20 & 164 \\
41 & U Bristol & 365.02 & $(61.72)$ & 24 & 107 \\
42 & U Exeter & 364.05 & $(70.19)$ & 18 & 131 \\
43 & Catholic U Leuven & 357.66 & $(38.39)$ & 24 & 216 \\
44 & European U Institute & 319.61 & $(45.36)$ & 23 & 106 \\
45 & U Groningen & 316.08 & $(41.93)$ & 24 & 179 \\
46 & U Glasgow & 313.79 & $(40.40)$ & 28 & 124 \\
47 & U Helsinki & 286.74 & $(100.96)$ & 11 & 92 \\
48 & Norwegian School of Econ & 286.23 & $(48.02)$ & 20 & 120 \\
49 & U Bologna & 262.55 & $(58.63)$ & 17 & 113 \\
50 & Free U Berlin & 255.00 & $(55.75)$ & 13 & 98 \\
51 & U Bocconi & 249.52 & $(63.78)$ & 24 & 100 \\
& & 157.52 & $(59.35)$ & 15 & 52 \\
52 & U Nova de Lisboa & 242.12 & $(54.82)$ & 12 & 70 \\
53 & U Newcastle & 238.81 & $(38.39)$ & 17 & 108 \\
54 & U Reading & 237.30 & $(41.37)$ & 18 & 136 \\
55 & U Manchester & 225.42 & $(28.85)$ & 22 & 82 \\
56 & U Birmingham & 223.51 & $(47.55)$ & 16 & 96 \\
57 & U Venezia & 218.16 & $(69.31)$ & 12 & 69 \\
58 & U College Dublin & 218.09 & $(57.71)$ & 10 & 84 \\
59 & U Dortmund & 211.87 & $(52.65)$ & 15 & 85 \\
60 & Institute for International Econ (Sweden) & 207.40 & $(40.73)$ & 21 & 47 \\
61 & U Bergen & 202.31 & $(38.92)$ & 10 & 57 \\
62 & U Bielefeld & 201.09 & $(28.15)$ & 13 & 64 \\
63 & U Cergy & 200.11 & $(40.81)$ & 11 & 60 \\
& Queen Mary and Westfield College & 208.37 & $(49.47)$ & 12 & 70 \\
64 & THEMA & 185.83 & $(35.84)$ & 15 & 83 \\
65 & Umea U & 184.22 & $(51.96)$ & 12 & 95 \\
66 & Lund U & 180.33 & $(26.41)$ & 10 & 76 \\
67 & HEC & 175.24 & $(39.55)$ & 14 & 53 \\
68 & Wissenschaftszentrum Berlin & 178.95 & $(45.41)$ & 14 & 82 \\
69 & U Nijmegen & 172.97 & $(46.76)$ & 12 & 40 \\
70 & Athens U Econ & 170.30 & $(33.13)$ & 12 & 61 \\
71 & Bank of England & 166.53 & $(38.82)$ & 23 & 62 \\
72 & CEMFI & 164.83 & $(44.86)$ & 12 & 62 \\
73 & U Edinburgh & 162.48 & $(33.08)$ & 12 & 84 \\
74 & U Leicester & 146.52 & $(27.14)$ & 11 & 57 \\
75 & Imperial College & 141.76 & $(27.73)$ & 13 & 72 \\
\hline & & & & & \\
\end{tabular}

This new ranking changes some positions which were however found to be statistically equivalent in the previous ranking: for instance LSE and Tilburg, Erasmus and Amsterdam. However, some departments are now ranked as equivalent while in the previous ranking they statistically dominated their present homologues: Oxford for Toulouse, Paris I for Bonn. Consequently, there is a change of information brought by considering a restricted set of journals which is statistically significant in some cases.

\section{California and top European departments}

Much has been said about the excellence of the US academic system. How do the best European can compare to the California ones? The US and the Californian academic systems are very heterogenous. 
There are 52 economic departments in California, but only 37 were visible in the JEL database, while only $31(60 \%)$ had at least one author above the minimum productivity level $z$. Finally, we found only 18 departments $(35 \%)$ which more than 10 productive authors. This visibility is in percentage comparable to that of Europe on average, but lower than that of the UK, the Netherlands and Belgium.

\subsection{Using the full list of journals}

We have selected the top economics department of each European country, adding the European University Institute for Italy, Oxford and Cambridge for the UK and Stockholm U for Sweden. We now match this list with the top Californian departments.

Table 11: California ranking using the full list of journals

\begin{tabular}{|c|c|c|c|c|c|}
\hline Rank & Institution & total score & std. dev. & authors & papers \\
\hline 1 & U CA, Berkeley & 4936.06 & $(389.32)$ & 182 & 1191 \\
\hline 2 & Stanford U & 4719.60 & $(314.19)$ & 189 & 1028 \\
\hline \multirow[t]{2}{*}{3} & UCLA & 3582.45 & $(270.22)$ & 154 & 812 \\
\hline & LSE & 2637.33 & (256.97) & 150 & 726 \\
\hline \multirow[t]{3}{*}{4} & U CA, Davis & 2491.72 & $(225.47)$ & 86 & 627 \\
\hline & Tilburg U & 2433.27 & $(242.47)$ & 108 & 618 \\
\hline & U Oxford & 2074.31 & (181.48) & 119 & 641 \\
\hline \multirow[t]{2}{*}{5} & U CA, San Diego & 2037.36 & $(279.61)$ & 60 & 409 \\
\hline & U Cambridge & 1919.53 & $(200.46)$ & 101 & 660 \\
\hline \multirow[t]{3}{*}{6} & U Southern CA & 1725.77 & $(133.50)$ & 91 & 455 \\
\hline & Catholic U Louvain & 1611.94 & $(210.16)$ & 73 & 489 \\
\hline & U Toulouse & 1331.90 & $(306.08)$ & 43 & 352 \\
\hline \multirow[t]{2}{*}{7} & U CA, Irvine & 1134.20 & $(167.38)$ & 47 & 276 \\
\hline & Stockholm School of Econ & 1066.09 & $(151.00)$ & 56 & 310 \\
\hline \multirow[t]{2}{*}{8} & CA Institute of Technology & 1008.14 & $(159.98)$ & 36 & 221 \\
\hline & U Autonoma Barcelona & 932.92 & $(117.24)$ & 46 & 238 \\
\hline \multirow[t]{5}{*}{9} & U CA, Santa Barbara & 954.01 & $(133.66)$ & 36 & 233 \\
\hline & Stockholm U & 935.42 & $(177.42)$ & 50 & 227 \\
\hline & U Bonn & 900.15 & $(89.01)$ & 57 & 218 \\
\hline & U Copenhagen & 824.28 & $(121.93)$ & 41 & 211 \\
\hline & U Oslo & 669.56 & $(102.56)$ & 38 & 174 \\
\hline \multirow[t]{2}{*}{10} & U CA, Santa Cruz & 664.01 & $(133.76)$ & 19 & 182 \\
\hline & U Vienna & 618.06 & $(92.83)$ & 37 & 169 \\
\hline 11 & U CA, Riverside & 605.88 & $(63.26)$ & 33 & 185 \\
\hline \multirow[t]{5}{*}{12} & Federal Reserve Bank of San Fran & 603.86 & $(84.42)$ & 30 & 170 \\
\hline & U Bologna & 476.61 & $(81.89)$ & 25 & 178 \\
\hline & European U Institute & 471.57 & $(56.55)$ & 29 & 121 \\
\hline & Athens U Econ & 422.67 & $(51.96)$ & 32 & 159 \\
\hline & U College Dublin & 400.50 & $(80.55)$ & 16 & 121 \\
\hline \multirow[t]{3}{*}{13} & Santa Clara U & 372.07 & $(50.28)$ & 22 & 99 \\
\hline & U Helsinki & 371.33 & $(111.22)$ & 14 & 104 \\
\hline & U Nova de Lisboa & 306.02 & $(70.20)$ & 14 & 75 \\
\hline 14 & CA State U, Fullerton & 267.30 & $(40.08)$ & 17 & 101 \\
\hline
\end{tabular}

Stanford and Berkeley have a score which is roughly twice that of the best European departments, but they are also slightly bigger in term of their number of productive academics. So Europe is not comparable to the best of US departments. However, the score of Californian departments decreases rapidly. UCLA is still far above, but best European departments are now comparable to Davis, 
San Diego and Southern California. European departments need on average more academics than Californian ones in order to get a similar total score, with the exception of Louvain and Toulouse.

\subsection{Testing}

Let us now try to qualify this ranking by examining the $t$ statistics given in Table 12 . The first three Californian departments (Berkeley, Stanford and UCLA) dominate clearly all the top European departments. Stanford and Berkeley are equivalent and dominate UCLA. Generally speaking, when a European department has a total score which is near to a Californian department, these two departments can be seen as equivalent because they have comparable standard deviations. Five top European departments (LSE, Tilburg, Oxford, Cambridge, Louvain) manage to clearly dominate nearly all the Californian departments which are ranked below them. But the other five European departments included in Table 12 (Toulouse, Stockholm U, Stockholm School of Econ, Barcelona, Bonn) do not statistically dominate the other departments that are ranked below them.

\subsection{Using the list of top journals}

When we adopt the short list of journals to rank departments, the ranking of Californian departments mainly does not change, but six European departments fall down in this ranking (LSE, Oxford, Cambridge, Stockholm School, Athens and Dublin). This is a clear illustration of what we have found before, that Californian authors publish in better journals than their European colleagues.

Table 13: California ranking based on top list

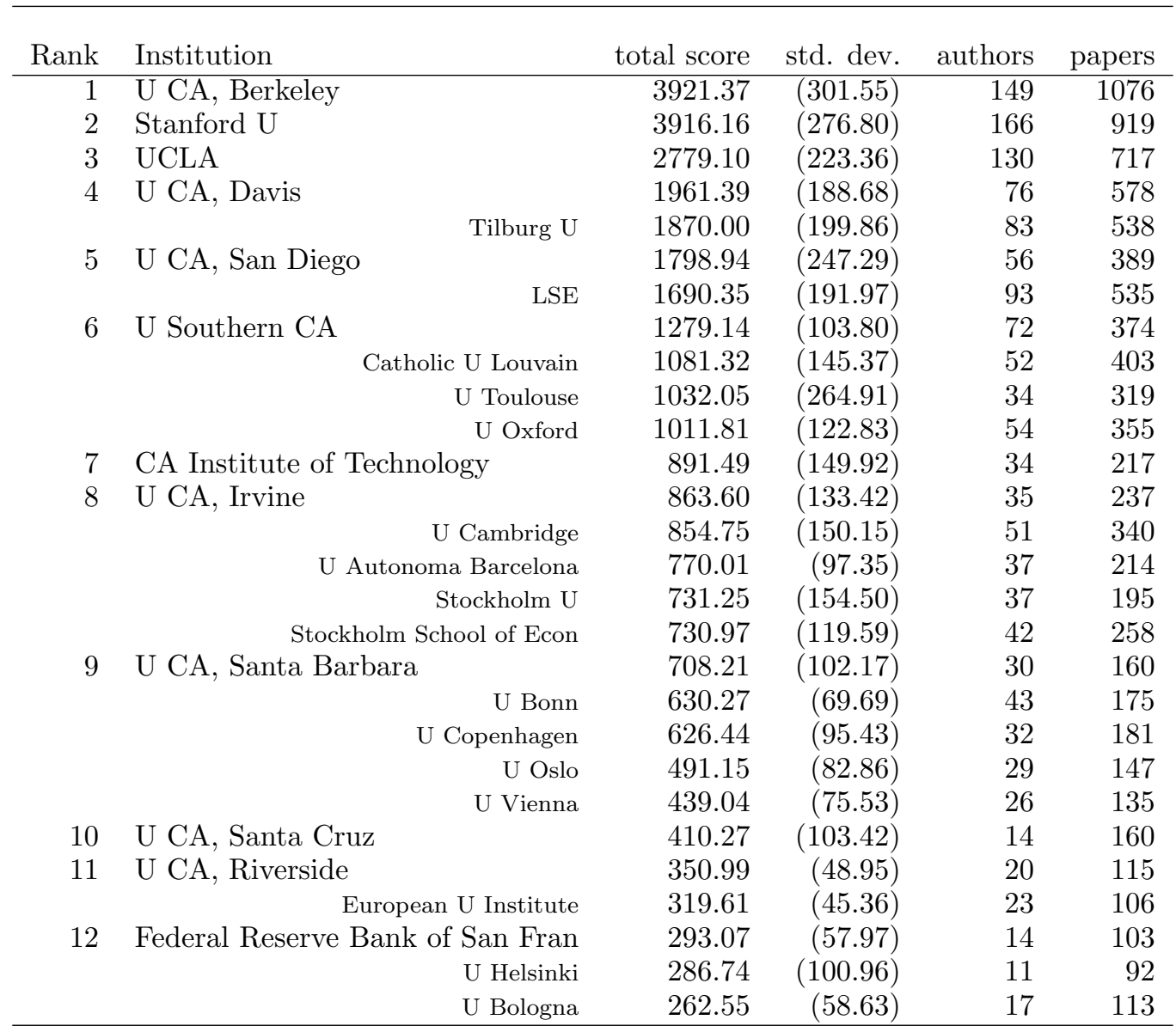


Table 12: Testing California versus Europe

\begin{tabular}{|c|c|c|c|c|c|c|c|c|c|c|}
\hline & Berk & Stan & UCLA & Lse & UCDv & Til & Oxf & UCSD & Cam & USCA \\
\hline Berk & 0.00 & 0.43 & 2.86 & 4.94 & 5.45 & 5.47 & 6.68 & 6.07 & 6.91 & 7.83 \\
\hline Stan & -0.43 & 0.00 & 2.75 & 5.14 & 5.79 & 5.78 & 7.32 & 6.41 & 7.54 & 8.81 \\
\hline UCLA & -2.86 & -2.75 & 0.00 & 2.54 & 3.12 & 3.18 & 4.65 & 4.00 & 4.96 & 6.19 \\
\hline Lse & -4.94 & -5.14 & -2.54 & 0.00 & 0.43 & 0.58 & 1.80 & 1.59 & 2.21 & 3.16 \\
\hline UCDv & -5.45 & -5.79 & -3.12 & -0.43 & 0.00 & 0.18 & 1.45 & 1.27 & 1.91 & 2.95 \\
\hline Til & -5.47 & -5.78 & -3.18 & -0.58 & -0.18 & 0.00 & 1.19 & 1.08 & 1.64 & 2.57 \\
\hline Oxf & -6.68 & -7.32 & -4.65 & -1.80 & -1.45 & -1.19 & 0.00 & 0.11 & 0.57 & 1.56 \\
\hline UCSD & -6.07 & -6.41 & -4.00 & -1.59 & -1.27 & -1.08 & -0.11 & 0.00 & 0.34 & 1.01 \\
\hline Cam & -6.91 & -7.54 & -4.96 & -2.21 & -1.91 & -1.64 & -0.57 & -0.34 & 0.00 & 0.81 \\
\hline USCA & -7.83 & -8.81 & -6.19 & -3.16 & -2.95 & -2.57 & -1.56 & -1.01 & -0.81 & 0.00 \\
\hline Lou & -7.54 & -8.25 & -5.78 & -3.10 & -2.87 & -2.57 & -1.67 & -1.22 & -1.06 & -0.46 \\
\hline Tou & -7.30 & -7.75 & -5.54 & -3.28 & -3.07 & -2.83 & -2.10 & -1.71 & -1.61 & -1.19 \\
\hline UCIr & -9.00 & -10.12 & -7.74 & -4.92 & -4.88 & -4.44 & -3.84 & -2.79 & -3.03 & -2.79 \\
\hline StoS & -9.30 & -10.52 & -8.17 & -5.29 & -5.30 & -4.81 & -4.30 & -3.08 & -3.42 & -3.30 \\
\hline Calt & -9.37 & -10.59 & -8.25 & -5.41 & -5.42 & -4.94 & -4.45 & -3.22 & -3.58 & -3.49 \\
\hline UCSB & -9.71 & -11.09 & -8.78 & -5.85 & -5.93 & -5.38 & -5.02 & -3.53 & -4.04 & -4.15 \\
\hline StoU & -9.38 & -10.53 & -8.22 & -5.47 & -5.46 & -5.01 & -4.51 & -3.35 & -3.69 & -3.59 \\
\hline Bar & -9.88 & -11.34 & -9.04 & -6.06 & -6.19 & -5.61 & -5.32 & -3.67 & -4.28 & -4.52 \\
\hline Bon & -10.14 & -11.74 & -9.47 & -6.41 & -6.63 & -5.97 & -5.85 & -3.91 & -4.68 & -5.21 \\
\hline UCSC & -10.44 & -11.97 & -9.77 & -6.87 & -7.07 & -6.46 & -6.35 & -4.48 & -5.28 & -5.74 \\
\hline & Lou & Tou & UCIr & StoS & Calt & $\begin{array}{l}\text { UCSB } \\
\end{array}$ & StoU & Bar & Bon & UCSC \\
\hline Berk & 7.54 & 7.30 & 9.00 & 9.30 & 9.37 & 9.71 & 9.38 & 9.88 & 10.14 & 10.44 \\
\hline Stan & 8.25 & 7.75 & 10.12 & 10.52 & 10.59 & 11.09 & 10.53 & 11.34 & 11.74 & 11.97 \\
\hline UCLA & 5.78 & 5.54 & 7.74 & 8.17 & 8.25 & 8.78 & 8.22 & 9.04 & 9.47 & 9.77 \\
\hline Lse & 3.10 & 3.28 & 4.92 & 5.29 & 5.41 & 5.85 & 5.47 & 6.06 & 6.41 & 6.87 \\
\hline $\mathrm{UCDv}$ & 2.87 & 3.07 & 4.88 & 5.30 & 5.42 & 5.93 & 5.46 & 6.19 & 6.63 & 7.07 \\
\hline Til & 2.57 & 2.83 & 4.44 & 4.81 & 4.94 & 5.38 & 5.01 & 5.61 & 5.97 & 6.46 \\
\hline Oxf & 1.67 & 2.10 & 3.84 & 4.30 & 4.45 & 5.02 & 4.51 & 5.32 & 5.85 & 6.35 \\
\hline UCSD & 1.22 & 1.71 & 2.79 & 3.08 & 3.22 & 3.53 & 3.35 & 3.67 & 3.91 & 4.48 \\
\hline Cam & 1.06 & 1.61 & 3.03 & 3.42 & 3.58 & 4.04 & 3.69 & 4.28 & 4.68 & 5.28 \\
\hline USCA & 0.46 & 1.19 & 2.79 & 3.30 & 3.49 & 4.15 & 3.59 & 4.52 & 5.21 & 5.74 \\
\hline Lou & 0.00 & 0.76 & 1.79 & 2.12 & 2.31 & 2.67 & 2.47 & 2.84 & 3.14 & 3.86 \\
\hline Tou & -0.76 & 0.00 & 0.57 & 0.78 & 0.94 & 1.14 & 1.13 & 1.22 & 1.36 & 2.02 \\
\hline UCIr & -1.79 & -0.57 & 0.00 & 0.30 & 0.55 & 0.85 & 0.82 & 1.00 & 1.25 & 2.24 \\
\hline StoS & -2.12 & -0.78 & -0.30 & 0.00 & 0.27 & 0.56 & 0.56 & 0.70 & 0.96 & 2.03 \\
\hline Calt & -2.31 & -0.94 & -0.55 & -0.27 & 0.00 & 0.26 & 0.31 & 0.38 & 0.60 & 1.69 \\
\hline UCSB & -2.67 & -1.14 & -0.85 & -0.56 & -0.26 & 0.00 & 0.08 & 0.12 & 0.34 & 1.57 \\
\hline StoU & -2.47 & -1.13 & -0.82 & -0.56 & -0.31 & -0.08 & 0.00 & 0.01 & 0.18 & 1.24 \\
\hline Bar & -2.84 & -1.22 & -1.00 & -0.70 & -0.38 & -0.12 & -0.01 & 0.00 & 0.23 & 1.55 \\
\hline Bon & -3.14 & -1.36 & -1.25 & -0.96 & -0.60 & -0.34 & -0.18 & -0.23 & 0.00 & 1.51 \\
\hline UCSC & -3.86 & -2.02 & -2.24 & -2.03 & -1.69 & -1.57 & -1.24 & -1.55 & -1.51 & 0.00 \\
\hline
\end{tabular}

Bold numbers indicate that the test is significant at the $10 \%$ level. 


\begin{tabular}{rcrrrr} 
Rank & Institution & total score & std. dev. & authors & papers \\
\hline 13 & Santa Clara U & 251.89 & $(40.93)$ & 17 & 77 \\
& U Nova de Lisboa & 242.12 & $(54.82)$ & 12 & 70 \\
& U College Dublin & 218.09 & $(57.71)$ & 10 & 84 \\
& Athens U Econ & 170.30 & $(33.13)$ & 12 & 61 \\
14 & CA State U, Fullerton & 145.18 & $(23.68)$ & 11 & 72 \\
\hline
\end{tabular}

\section{Conclusion}

We have managed to obtain a ranking of European economics departments and to compare the top European departments to Californian departments. We showed that the reference set of journals may have a crucial influence on the obtained ranking. But the criterion used for ranking may also change the ranking a lot.

We have shown that the production of a department can be seen as the outcome of a random variable characterised by a mean and a standard deviation. Consequently the ranking we have produced must be seen as one particular realisation of a set of random variables and departments having slightly different total scores can nevertheless be considered as statistically equivalent.

The fact that some departments are better than others is the fruit of particular educational policies, which may have been adopted a very long time ago. Sometimes, it may also be the fruit of recent events or decisions (the German reunification for instance). Educational systems have different organisations. Some countries have developed separate research institutions of various importance. In Belgium, FNRS is rather small and mainly distributes funds. In France, CNRS plays a major role and employs 11000 full time researchers (200 in economics). Germany has the Max Plank Institutes, Italy the "Consiglio Nazionale delle Ricerche" or CNR, England the "Economics and Social Research Council" or ESRC which distributes funds. Spain has the CSIC which employs full time researchers mainly in Madrid and in Barcelona where is located the Institute of Economic Analysis. Some countries organise promotion and department funding on the basis of publications: Netherlands, the UK and more recently Spain. In most countries, academics get an immediate tenure. In California and the UK, academics get their tenure after a rather long time. Wages are fixed in some countries or negotiated in others. All these principles of organisation do have an impact on the output performance of the academic system. We plan to answer this type of question in future work.

\section{Appendix: Journal ranking}

We give the list of the 69 top journals that were used for ranking departments.

Table 14: Top journal ranking

\begin{tabular}{l|c}
\hline & Score \\
\hline Journals & 10 \\
American-Economic-Review & 10 \\
Econometrica & 10 \\
Journal-of-Economic-Theory & 10 \\
Journal-of-Political-Economy & 10 \\
Quarterly-Journal-of-Economics & 10 \\
Review-of-Economic-Studies & 8 \\
American-Political-Science-Review & 8 \\
International-Economic-Review & 8 \\
Journal-of-Econometrics & 8 \\
Journal-of-Economic-Literature & \\
\hline
\end{tabular}




\begin{tabular}{|c|c|}
\hline Journals & Score \\
\hline Journal-of-Finance & 8 \\
\hline Journal-of-Financial-Economics & 8 \\
\hline Journal-of-International-Economics & 8 \\
\hline Journal-of-Labor-Economics & 8 \\
\hline Journal-of-Law-and-Economics & 8 \\
\hline Journal-of-Monetary-Economics & 8 \\
\hline Journal-of-Money,-Credit,-and-Banking & 8 \\
\hline Journal-of-Public-Economics & 8 \\
\hline Journal-of-the-American-Statistical-Association & 8 \\
\hline Michigan-Law-Review & 8 \\
\hline Rand-Journal-of-Economics & 8 \\
\hline Review-of-Economics-and-Statistics & 8 \\
\hline Yale-Law-Journal & 7 \\
\hline Accounting-Review & 6 \\
\hline American-Journal-of-Agricultural-Economics & 6 \\
\hline Brookings-Papers-on-Economic-Activity & 6 \\
\hline Demography & 6 \\
\hline Econometric-Theory & 6 \\
\hline Economica & 6 \\
\hline Economic-Journal & 6 \\
\hline Economics-Letters & 6 \\
\hline Economic-Theory & 6 \\
\hline European-Economic-Review & 6 \\
\hline Games-and-Economic-Behavior & 6 \\
\hline Industrial-and-Labor-Relations-Review & 6 \\
\hline International-Journal-of-Game-Theory & 6 \\
\hline Journal-of-Applied-Econometrics & 6 \\
\hline Journal-of-Banking-and-Finance & 6 \\
\hline Journal-of-Business-and-Economic-Statistics & 6 \\
\hline Journal-of-Comparative-Economics & 6 \\
\hline Journal-of-Development-Economics & 6 \\
\hline Journal-of-Economic-Behavior-and-Organization & 6 \\
\hline Journal-of-Economic-Dynamics-and-Control & 6 \\
\hline Journal-of-Economic-Growth & 6 \\
\hline Journal-of-Economic-History & 6 \\
\hline Journal-of-Economic-Methodology & 6 \\
\hline Journal-of-Economic-Perspectives & 6 \\
\hline Journal-of-Economics-and-Management-Strategy & 6 \\
\hline Journal-of-Environmental-Economics-and-Management & 6 \\
\hline Journal-of-Financial-and-Quantitative-Analysis & 6 \\
\hline Journal-of-Health-Economics & 6 \\
\hline Journal-of-Human-Resources & 6 \\
\hline Journal-of-Industrial-Economics & 6 \\
\hline Journal-of-Law,-Economics-and-Organization & 6 \\
\hline Journal-of-Mathematical-Economics & 6 \\
\hline Journal-of-Risk-and-Insurance & 6 \\
\hline Journal-of-Risk-and-Uncertainty & 6 \\
\hline Journal-of-Urban-Economics & 6 \\
\hline
\end{tabular}




\begin{tabular}{l|c}
\hline & \\
Journals & Score \\
\hline Macroeconomic-Dynamics & 6 \\
Marketing-Science & 6 \\
Mathematical-Methods-of-Operations-Research & 6 \\
National-Tax-Journal & 6 \\
Oxford-Bulletin-of-Economics-and-Statistics & 6 \\
Public-Choice & 6 \\
Regional-Science-and-Urban-Economics & 6 \\
Scandinavian-Journal-of-Economics & 6 \\
Social-Choice-and-Welfare & 6 \\
Urban-Studies & 6 \\
\hline
\end{tabular}

\section{References}

Amir R. (2001) Impact-adjusted citations as a measure of journal quality. Mimeo, CORE, Université catholique de Louvain.

Bauwens L. (1998). A new method to rank university research and researchers in economics in Belgium. Mimeo. CORE, Université catholique de Louvain.

Bauwens L. (1999) Economic Research In Belgian Universities. http://www.core.ucl.ac.be /econometrics /Bauwens /rankings /rankings.htm

Burton M.P. and E. Phimister (1995) Core journals: a reappraisal of the Diamond list. The Economic Journal 105, 361-373.

Combes P.P. and L. Linnemer (2001) La publication d'articles de recherche en économie en France. Annales d'Economie et de Statistique 62, 5-47.

Conroy M. and R. Dusansky (1995) The productivity of economics departments in the US: publications in the core journals. Journal of Economic Literature 33, 1966-1971.

Coupé Tim (2000) Revealed Performances Worldwide Rankings of Economists and Economics Departments. Mimeo, ECARES Université Libre de Bruxelles.

Cribari-Neto F., M. Jensen and A. Novo (1999). Research in Econometric Theory: Quantitative and Qualitative Productivity Rankings. Econometric Theory, 15, 719-752.

Dusansky R. and C.J. Vernon (1998) Ranking of US economics departments. Journal of Economic Perspectives 12, 157-170.

Feinberg, R. M. (1998). Correspondence. Ranking economics departments. Journal of Economic Perspective 12(4), pp. 231-232.

Foster J., J. Greer and E. Thorbecke (1984) A class of decomposable poverty measures, Econometrica $52(3), 761-766$.

Gans J.S. and G.B. Shepherd (1994) How are the mighty fallen: rejected classic articles by leading economists. Journal of Economic Perspectives 8(1), 165-179.

Griliches Z. and L. Einav (1998). Correspondence. Ranking economics departments. Journal of Economic Perspectives 12(4), 233-235.

Kalaitzidakis P., T.P. Mamuneas and T. Stengos (1999) European economics: an analysis based on publications in the core journals. European Economic Review 43, 1150-1168. 
Kirman, A. and Dahl, M. (1994) Economic research in Europe. European Economic Review 38, 505-522.

Laband D. and M. Piette (1994) The relative impact of Economics Journals. Journal of Economic Literature 32, 640-666.

Liebowitz S. and J. Palmer (1984) Assessing the relative impacts of economics journals. Journal of Economic Literature 22, 77-88.

Lubrano M. and C. Protopopescu (2002) Density inference for ranking european research systems in the field of economics. Mimeo, GREQAM. http://durandal.cnrs-mrs.fr/PP/lubrano/papers/wplotka.ps.

van Damme Eric (1996). Measuring Quality of academic journals and scientific productivity of researchers. Unpublished mimeo, CenTer, Tilburg University. 